\title{
Development of Potent and Effective Synthetic SARS-CoV-2 Neutralizing Nanobodies
}

Maxwell A. Stefan ${ }^{\dagger}$, Yooli K. Light ${ }^{\star}$, Jennifer L. Schwedler ${ }^{\mp}$, Peter R. Mcllroy ${ }^{\mp}$, Colleen M. Courtney ${ }^{\mp}$, Edwin A. Saada ${ }^{\dagger}$, Christine E. Thatcher ${ }^{\mp}$, Ashlee M. Phillips ${ }^{\ddagger}$, Feliza A. Bourguet ${ }^{\ddagger}$, Catherine M. Mageeney ${ }^{\dagger}$, Summer A. McCloy ${ }^{\ddagger}$, Nicole M. Collette ${ }^{\ddagger}$, Oscar A. Negrete $^{\mp}$, Joseph S. Schoeniger ${ }^{\dagger}$, Dina R. Weilhammer ${ }^{\ddagger}$, Brooke Harmon $^{\dagger \#}$

† Systems Biology Department, Sandia National Laboratories, Livermore, CA $\mp$ Biotechnology and Bioengineering Department, Sandia National Laboratories, Livermore, CA

$\ddagger$ Biosciences and Biotechnology Division, Lawrence Livermore National Laboratories, Livermore, CA

${ }^{*}$ Contributed equally, listed alphabetically

Corresponding author (\#)

Brooke Harmon, Ph.D.

Sandia National Laboratories

P.O. Box 969, MS 9292

Livermore, CA 94550

Phone: (925) 294-3023

Fax: (925) 294-3020

45 bharmon@sandia.gov 
Abstract

The respiratory virus responsible for Coronavirus disease 2019 (COVID-19), Severe acute respiratory syndrome coronavirus 2 (SARS-2), has impacted nearly every aspect of life worldwide, claiming the lives of over 2.5 million people globally, at the time of this publication. Neutralizing nanobodies $\left(\mathrm{V}_{\mathrm{H}} \mathrm{H}\right)$ represent a promising therapeutic

51 intervention strategy to address the current SARS-2 pandemic and provide a powerful

52 toolkit to address future virus outbreaks. Using a synthetic, high-diversity $\mathrm{V}_{\mathrm{H}} \mathrm{H}$

53 bacteriophage library, several potent neutralizing $\mathrm{V}_{\mathrm{H}} \mathrm{H}$ antibodies were identified and

54 evaluated for their capacity to tightly bind to the SARS-2 receptor-binding domain (RBD),

55 to prevent binding of SARS-2 spike (S) to the cellular receptor Angiotensin-converting enzyme 2 (ACE2), and to neutralize viral infection. Preliminary preclinical evaluation of

57 multiple nanobody candidates demonstrate that they are prophylactically and 58 therapeutically effective in vivo against wildtype SARS-2. The identified and characterized nanobodies described herein represent viable candidates for further preclinical evaluation 60 and another tool to add to our therapeutic arsenal to address the COVID-19 pandemic. 


\section{Author Summary}

62 To fully address the on-going pandemic caused by severe acute respiratory syndrome

63 coronavirus 2 (SARS-2), it will be important to have both vaccines and therapeutic

64 strategies to prevent and mitigate the effects of SARS-2. In this study, we describe the

65 identification and characterization of potently neutralizing humanized single domain

66

67

68

77 heavy chain $\left(\mathrm{V}_{\mathrm{H}} \mathrm{H}\right)$ antibodies that have binding affinity for both the original Wuhan strain and widely circulating B.1.1.7/UK strain. $\mathrm{V}_{\mathrm{H}} \mathrm{H}$ antibodies have the same therapeutic potential as conventional antibodies in half the size and with greater stability and solubility. Using a synthetic humanized high-diversity $V_{\mathrm{H}} \mathrm{H}$ phage library we identified several candidates with strong affinity for the SARS-2 spike that block the interaction of SARS-2 spike with the cellular receptor ACE2, and effectively neutralize infection with SARS-2 in vitro. By sequencing viral escape mutants generated in the presence of each $\mathrm{V}_{\mathrm{H}} \mathrm{H}$ we mapped the binding sites of the $\mathrm{V}_{\mathrm{H}} \mathrm{H}$ antibodies and assessed their affinity against newly emerging SARS-2 variants. Finally, we demonstrate that two of these $\mathrm{V}_{\mathrm{H}} \mathrm{H}$ antibodies show prophylactic and therapeutic efficacy in vivo against challenge with SARS-2. This study establishes that screening highly diverse $\mathrm{V}_{\mathrm{H}} \mathrm{H}$ phage libraries against viral threats can yield highly effective therapeutic agents in real time. 


\section{Introduction}

The novel respiratory virus, severe acute respiratory syndrome coronavirus 2 (SARS-2), has infected over 146 million and killed over 3 million people worldwide at the time of this publication(1), causing the worst global health crisis since the 1918 Spanish influenza pandemic. In addition to the cost of lives lost to COVID-19, this virus has wreaked havoc on the global economy and highlighted the threat that emerging diseases pose to global security.(2) It is important not only to work to develop effective vaccines for pre-exposure prophylaxis, but to create new treatments to prevent and mitigate severe disease.

Viral neutralizing antibodies are an effective therapeutic intervention for COVID19, as the current pandemic response has shown. High titer convalescent plasma has emergency use authorization by the U.S. FDA for the treatment of hospitalized patients early in the disease course and/or with impaired humoral immunity; however, batch-tobatch variability results in various levels of success, limiting its reliability as a treatment.(3) Monoclonal antibody therapies offer improved properties due to their target specificity, uniformity, favorable pharmacokinetics, and their ability to potently block cell entry, the first step of viral infection.(4-7) More recently, promising clinical trial data demonstrating that a single intravenous infusion of monoclonal antibody cocktail significantly reduced COVID-19 related hospitalization and death in comparison to placebo. $(8,9)$ These results and other clinical trial findings have resulted in emergency use authorization for several cocktails by the FDA for people 12 years and older who test positive for SARS-2 and are at high risk for progressing to severe COVID-19.(8, 9) Methods for improved development and characterization of novel neutralizing antibodies can be part of a critical toolset to 
combat the COVID-19 pandemic and future epidemics, by providing lower cost, easier manufacturability, and diverse functionality, including response to emerging variants.

Nanobodies $\left(\mathrm{V}_{\mathrm{H}} \mathrm{H}\right)$ are the variable region of single-domain heavy chain antibodies (sdAbs), which lack the light chain and the $\mathrm{CH} 1$ domain, are derived from camelids, and are smaller $(\sim 75 \mathrm{kDa})$ than human or murine immunoglobulin $\mathrm{G}(\lg \mathrm{G})$ antibodies (150kDa).(10) $\mathrm{V}_{\mathrm{H}} \mathrm{H}$ antibodies are highly soluble, stable, extremely versatile, and have unique structural attributes in their complementarity determining region 3 (CDR3) loop which can facilitate binding to antigen sites inaccessible to traditional $\lg G$ antibodies.(11, 12) Neutralization of SARS-2 is achieved by targeting antibodies to the spike (S) receptorbinding domain (RBD), which engages the Angiotensin-converting enzyme (ACE2) receptor to facilitate cell entry. The $S$ protein is heavily glycosylated, limiting viable epitope availability with potential for therapeutic efficacy.(13) Compact $V_{H} H$ antibodies may have access to alternate epitopes on the SARS-2 S protein that are sterically inaccessible to traditional antibodies.

Herein, we describe a rapid discovery process for SARS-2 $\mathrm{V}_{\mathrm{H}} \mathrm{H}$ antibody therapeutics, going from molecular discovery of high-affinity variable regions to demonstration of therapeutic efficacy of fully humanized $\mathrm{V}_{\mathrm{H}} \mathrm{H}$ antibodies in mice infected with SARS-2. We describe the construction of a high-diversity synthetic humanized $V_{\mathrm{H}} \mathrm{H}$ phage library $\left(\sim 3.2 \times 10^{10}\right)$ that was used to identify several $\mathrm{V}_{\mathrm{H}} \mathrm{H}$ antibodies that are highaffinity binders to SARS-2 S protein and RBD. The top $\mathrm{V}_{\mathrm{H}} \mathrm{H}$ candidates were produced as human single-domain heavy chain antibodies (hlgG1 Fc) and were evaluated for their ability to block the interaction between purified SARS-2 $S$ and the ACE2 receptor. Effective $\mathrm{V}_{\mathrm{H}} \mathrm{H}$ antibodies were then screened for their ability to block infection of Vero 
cells with SARS-2 pseudotyped vesicular stomatitis virus (VSV-SARS-2-GFP), followed by verification of neutralization of wildtype (WT) SARS-2 (USA-WA 1/2020). The epitope targets were mapped by sequencing neutralization escape mutants generated in the presence of each $\mathrm{V}_{\mathrm{H}} \mathrm{H}$. The binding affinity of the $\mathrm{V}_{\mathrm{H}} \mathrm{H}$ antibodies to RBD with mutations generated in this study or from circulating variants was assessed with kinetic studies using biolayer interferometry (BLI). We also demonstrate that two of these $\mathrm{V}_{\mathrm{H}} \mathrm{H}$ antibodies show efficacy in vivo both prophylactically and therapeutically against challenge with fully virulent $W T$ SARS-2.

\section{Materials and Methods \\ DNA Manipulation and Production of Proteins}

pSF-CMV-SARS-2-S was constructed as follows. DNA fragments encoding amino acids 1-1208 of the SARS-2 S gene (GenBank:MN908947.3) were amplified as several independent fragments to introduce several mutations described in Wrapp et. al. from a vector containing the full-length codon optimized S gene.(14) Additionally, a double stranded DNA fragment encoding a C-terminal T4 fibritin trimerization domain, TEV cleavage site, Twin-Step-Tag, and octahistadine was commercially obtained. pSF-SARS2-RBD was produced by commercial production of double stranded DNA encoding a Nterminal Kozak, a signal peptide (MDWTWRFLFVVAAATGVQS), 319-577 of the SARS2 S gene (GenBank:MN908947.3), a TEV site, and a C-terminal, decahistadine tag. Mutant SARS-2 RBDs were produced by site-directed mutagenesis. All fragments were synthesized commercially (IDT) and terminal fragments had overlapping sequence with the downstream digested vector. All DNA fragments and pSF-CMV vector restriction digested with EcoRI and BamHI were assembled using NEBuilder HiFi DNA master. 

fusion proteins were produced as follows. pAce2-huFc was produced by subcloning the ectodomain on human ACE2 (Sino Biological) into pCR-Fc using the Notl and BamHI restriction sites. To produce Ace2-rbFc (rabbit Fc domain), a gBlock (IDT) of this same region of Ace2 was subcloned into pFUSE rlgG-Fc2.

Soluble SARS-2 S and RBD were both produced by transient expression in 157 Expi293F suspension cells. Cells were transfected with $1 \mu \mathrm{g} / \mathrm{mL}$ plasmid at a density of $3.0 \times 10^{6}$ cells/mL using Expifectamine. Cells were supplemented as instructed by the manufacturer and grown at $37^{\circ} \mathrm{C}$ with $8 \% \mathrm{CO}_{2}$. Cell supernatant was harvested on day 4 by centrifugation at $4,000 \times \mathrm{g}$ for $30 \mathrm{~min}$ at $4^{\circ} \mathrm{C}$. Clarified supernatant was passed through a $0.22 \mu \mathrm{m}$ filter and then applied to a $5 \mathrm{~mL}$ HisTrap Excel column preequilibrated with 10 $\mathrm{mM}$ Tris (pH 8.0), $300 \mathrm{mM} \mathrm{NaCl}$ for SARS-2 S and $20 \mathrm{mM}$ phosphate (pH 7.4), $300 \mathrm{mM}$ $\mathrm{NaCl}$ for SARS-2 RBD. The column was washed with 10 column volumes equilibration buffer followed by 5 column volumes equilibration buffer with $20 \mathrm{mM}$ imidazole. The $\mathrm{S}$ and RBD proteins were eluted with a step gradient to $500 \mathrm{mM}$ imidazole. Fractions containing SARS-2 S protein were pooled and dialyzed in 20 mM HEPES (pH 8.0), 200 $\mathrm{mM} \mathrm{NaCl}$ prior to concentration. Protein was then concentrated and filtered prior to application to a Enrich 650 SEC column equilibrated with dialysis buffer for SARS-2 S and PBS for SARS-2 RBD. Purified SARS-2 proteins were stored at $-80^{\circ} \mathrm{C}$.

ACE2-huFc, ACE2-rbFc, and $\mathrm{V}_{\mathrm{H}} \mathrm{H}$-huFc antibodies were produced by transient 171 expression in $\mathrm{CHO}-\mathrm{S}$ cells using the ExpiCHO expression system. In brief, cells were

172 transfected at a density of $6 \times 10^{6}$ cells $/ \mathrm{mL}$ and grown for 18 hours at $37^{\circ} \mathrm{C}$ with $8 \% \mathrm{CO} 2$.

173 Cells were then supplemented as per the manufacture's guidelines and transferred to 32 
$174{ }^{\circ} \mathrm{C}$ with $5 \% \mathrm{CO} 2$. Cell supernatant containing soluble protein was harvested on day 10 by centrifugation at $4,000 \times \mathrm{g}$ for $30 \mathrm{~min}$ at $4^{\circ} \mathrm{C}$. Clarified supernatant was passed through a $0.22 \mu \mathrm{m}$ filter and the applied to a $1 \mathrm{~mL}$ MabSelect PrismA column. The column was washed with $20 \mathrm{mM}$ sodium phosphate (pH 7.4), $150 \mathrm{mM} \mathrm{NaCl}$. ACE2-Fc fusion proteins were eluted with $100 \mathrm{mM}$ sodium citrate $(\mathrm{pH} 3.0)$ and immediately neutralized with $1 \mathrm{M}$

179 Tris ( $\mathrm{pH}$ 9.0). Protein was then concentrated and filtered before application to a Enrich 650 SEC column equilibrated with $10 \mathrm{mM}$ sodium phosphate $(\mathrm{pH} 7.2), 140 \mathrm{mM} \mathrm{NaCl}$. Purified ACE2-huFc, ACE2-rbFc, and $\mathrm{V}_{\mathrm{H}} \mathrm{H}$-huFc were stored at $-80^{\circ} \mathrm{C}$. $\mathrm{V}_{\mathrm{H}} \mathrm{H}$-huFc antibodies identified from screening were commercially obtained from GenScript.

Synthetic $\mathrm{V}_{\mathrm{H}} \mathrm{H}$ library was designed as follows. A high diversity library was specifications mentioned above as well as terminal flanking Bgll restriction sites were synthetically produced commercially by Twist Bioscience. A humanized $V_{H} H$ framework characterized in Moutel et. al. was used to house the designer CDRs.(16) 
197 Step 2: $98^{\circ} \mathrm{C}, 10$ seconds; $68^{\circ} \mathrm{C}, 10$ seconds; $72^{\circ} \mathrm{C}, 15$ seconds, 5 cycles; Step $3: 72^{\circ} \mathrm{C}$,

19810 minutes, 1 cycle; Step 4: $12^{\circ} \mathrm{C}$, hold). Amplified DNA was pooled and purified by

199 Monarch Nucleic Acid Purification Kit. The library was digested with 5U/ug DNA Sfil at

$20050^{\circ} \mathrm{C}$ for 16 hours. Digest reactions were again column purified as previously mentioned.

201 Ligations were set up as follows. pADL20c (205 $\mu \mathrm{g})$ previously digested with Bgll and

202 treated with rSAP was added to a $40 \mathrm{~mL}$ reaction containing the linear digested library

$203(42 \mu \mathrm{g})$ at a vector to insert ratio of 1:2, $1 \mathrm{mM}$ ATP and 1,100,000 units of T4 Ligase. The

204 reaction was allowed to proceed at $16^{\circ} \mathrm{C}$ for 16 hours, then at $37^{\circ} \mathrm{C}$ for 1 hour, and lastly

205 was heat inactivated at $70^{\circ} \mathrm{C}$ for 20 minutes. DNA was purified and concentrated by a

206 modified ethanol precipitation protocol utilizing tRNA carrier at $15 \mu \mathrm{g} / \mathrm{mL}$.

Transformation of the library into TG1 E. coli was performed as follows. A total of

9 liters of fresh electrocompetent TG1 E. coli cells were produced and 150

electroporations performed. To $350 \mu \mathrm{L}$ cells, $15 \mu \mathrm{L}$ of ligated DNA was added and electroporation performed. After 1 -hour recovery with the addition of $650 \mu \mathrm{L} \mathrm{SOC}$ at $37^{\circ} \mathrm{C}$, cells were plated on 2xYT agar plates supplemented with $100 \mathrm{mM}$ glucose and $100 \mu \mathrm{g} / \mathrm{mL}$ carbenicillin (2xYT-GA). E. coli was harvested after growth at $37^{\circ} \mathrm{C}$ for 16 hours, supplemented with glycerol to $10 \%$, and stored at $-80^{\circ} \mathrm{C}$ in aliquots for further use.

214 Diversity of the nanobody library was determined by both NGS and colony PCR.

The $\mathrm{V}_{\mathrm{H}} \mathrm{H}$ library was added to $2 x \mathrm{YT}-\mathrm{GA}$ to a final $\mathrm{OD}_{600}$ of 0.08 and allowed to

216 grow at $37^{\circ} \mathrm{C}$ until an $\mathrm{OD}_{600}$ of 0.5 was reached. Superinfection with $\mathrm{CM} 13$ (ADL) was

217 performed with $2.0 \times 10^{12}$ helper phage per liter of $E$. coli culture for 15 minutes without 
supplemented with $100 \mu \mathrm{g} / \mathrm{mL}$ carbenicillin and $50 \mu \mathrm{g} / \mathrm{mL}$ kanamycin (2xYT-AK). E. coli were grown overnight with shaking at $28^{\circ} \mathrm{C}$.

Supernatant containing packaged phagemid was clarified by centrifugation at $6,000 \times g$ for 15 minutes and supplemented with one-fourth volume $20 \%$ PEG-8000 and $2.5 \mathrm{M} \mathrm{NaCl}$. Phage were precipitated overnight at $4^{\circ} \mathrm{C}$ and were collected by centrifugation at $5,500 \times \mathrm{g}$ for 60 minutes at $4^{\circ} \mathrm{C}$. The pellet containing phage was resuspended in PBS and centrifugated for 15 minutes at $5,500 \times \mathrm{g}$ to remove $E$. coli particulates. Clarified phage was again precipitated as mentioned above and incubated on ice for 60 minutes. The phage was finally centrifuged at $17,900 \mathrm{x} g$ for 10 minutes at $4^{\circ} \mathrm{C}$, the supernatant was removed, and the pellet was again centrifuged at $17,900 \times \mathrm{g}$ for 1 minute to remove trace amounts of PEG-8000. The pellet was resuspended in PBS and passed through a $0.22 \mu \mathrm{m}$ filter before determining the colony forming units (CFU).

\section{Next-Generation Sequencing}

All samples for NGS were processed as follows. The minimum region containing all 3 CDR domains, approximately 300 bps, was excised from the pADL20c backbone by two-step restriction digests, $B g / /$ followed by $D d e / / B s t E / /$ double digests on the gel-purified small fragment from the Bgll restriction reaction. The sequencing library was prepared using NEBNext ${ }^{\circledR}$ Ultra ${ }^{\mathrm{TM}}$ II DNA Library Prep Kit for Illumina ${ }^{\circledR}(\mathrm{NEB})$ and $x \mathrm{Gen}^{\mathrm{TM}}$ UDI-UMI Adapters (IDT) as instructed in the manufacture's manuals and sequenced on Illumina NextSeq 500/550 platform with High Output v2.5 300-cycles, paired-end mode. BCL files were converted to FASTQ and demutiplexed using the bcl2fastq script from Myllumina (https://my.illumina.com). The quality filtering and adaptor trimming were performed using fastp (https://github.com/OpenGene/fastp) with following parameters, -q 30 -I 100 -x 7. R2 
243 read was reformatted to be reverse complemented and merged with R1 read using BBTools (BBMap, https://sourceforge.net/projects/bbmap/).(17) Three CDR domains with correct sequence lengths were extracted, concatenated and translated and counted unique amino acid sequences using a custom python script.

A total of four rounds of affinity selection were conducted, three rounds against soluble full-length SARS-2 $S$ and a final round against SARS-2 RBD. Panning was performed by immobilizing antigen in 96-well Immulon® HBX microplates. For the first

251 round of panning $3 \mu \mathrm{g}$ SARS-2 $\mathrm{S}$ was immobilized in $50 \mu \mathrm{L}$ coating buffer $(100 \mathrm{mM}$

$252 \mathrm{NaHCO}_{3}(\mathrm{pH} 8.3), 150 \mathrm{mM} \mathrm{NaCl}$ ) overnight at $4^{\circ} \mathrm{C}$. Wells containing antigen were washed

253 five times with $300 \mu \mathrm{L}$ PBS-t (phosphate buffered saline supplemented with $0.05 \%$

254 Tween-20). Wells were blocked with $300 \mu \mathrm{L}$ Pierce PBS Protein Free Blocking Solution

255 for 2 hours. After another round of washing, $200 \mu \mathrm{L}$ of $2.5 \times 10^{12} \mathrm{CFU} / \mathrm{mL}$ phage were added to each well in blocking buffer and allowed to incubate with vigorous shaking at $25^{\circ} \mathrm{C}$ for 2 hours. Wells were extensively washed with increasing amounts of Tween-20, with a peak concentration of $0.5 \%$ Tween-20. Phage were eluted with the addition of 50 $\mu \mathrm{L}$ of elution buffer $(10 \mathrm{mM}$ Tris $\mathrm{pH} 7.4,137 \mathrm{mM} \mathrm{NaCl}, 1 \mathrm{mM} \mathrm{CaCl}$ and $100 \mu \mathrm{g} / \mathrm{mL}$ Trypsin) by incubating for 30 minutes at $37^{\circ} \mathrm{C}$. Eluate was removed and pooled and a second $50 \mu \mathrm{L}$ of elution buffer was added for 20 minutes. This was collected and pooled with the first round of elution buffer. Eluted phage was added to an equal volume of log phage TG1 E. coli for reamplification and quantification. 
was conducted with an input of $10^{11} \mathrm{CFU}$ phage. With each round of panning, washing was progressively increased from 12 washes in the first round to 15 , then to 21 for the final two rounds. For all rounds after the first, a maximum of $1 \%$ Tween-20 used for washing. The plates were then extensively washed with PBS to remove excess Tween20. Additionally, the blocking solution for each round of panning was cycled. For the second round PBS-t supplemented with $1 \%$ bovine serum albumin (BSA) (w/v) was used, for the third round PBS-t supplemented with $2 \%$ non-fat milk, and for the final round BSA was again used. A denaturing step was conducted before the last round of panning against the SARS-2 RBD to remove unstable clones by heating the phage to $70^{\circ} \mathrm{C}$ for 15 minutes before panning. All other elution, reamplification, and tittering steps were conducted as mentioned above.

\section{Polyclonal and Monoclonal Phage ELISA}

Polyclonal phage ELISA was used to characterize antigenic enrichment and specificity for each round of panning. Multiple antigens were tested including BSA, SARSCoV-1 S, SARS-2 S, and SARS-2 RBD. Immulon HBX microtiter 384 well plates were coated with at $0.05 \mu \mathrm{g} /$ well of each antigen overnight at $4^{\circ} \mathrm{C}$. Plates were washed 5 times with PBS-t and blocked with $50 \mu \mathrm{L}$ of PBS with $2 \%$ non-fat milk and $0.2 \%$ Tween-20 (MPBS-t). Plates were washed and $10^{9}$ phage from the unenriched library and each round of panning was added to each well for all of the antigens in blocking solution. After 2 hours of shaking at $25^{\circ} \mathrm{C}$ the plates were again washed five-times and mouse anti-M13 coat protein (Thermo) was added 1:2000 in MPBS-t for 1 hour. The plates were again washed, and rabbit anti-mouse IgG HRP (Thermo) was added 1:1000 in MPBS-t for 1 hour with shaking. The plates were finally washed 5 times with PBS-t and developed with TMB Ultra 
substrate (Thermo) and quenched with $2 \mathrm{M} \mathrm{H}_{2} \mathrm{SO}_{4}$ before reading the absorbance at 450 $\mathrm{nm}$. Monoclonal phage ELISAs were performed in a similar fashion to the polyclonal ELISA mentioned above with homogeneous preparations of $\mathrm{V}_{\mathrm{H}} \mathrm{H}$-phage to validate individual clones.

\section{$\underline{\mathrm{V}}_{\mathrm{H}} \underline{\mathrm{H}-\mathrm{huFC} \text { ELISA }}$}

Indirect ELISAs were performed as follows. Full-length soluble SARS-2 S or RBD were immobilized on Immulon 384-well microtiter plates $(0.05 \mu \mathrm{g} /$ well $)$ overnight at $4{ }^{\circ} \mathrm{C}$ in coating buffer. After washing, plates were blocked for 2 hours with Pierce PBS Protein Free Blocking buffer (Thermo). Serial dilutions of $\mathrm{V}_{\mathrm{H}} \mathrm{H}-\mathrm{huFc}$ antibodies in blocking buffer were added to plates for 2 hours after washing. Secondary antibody, goat anti-human $\mathrm{H}+\mathrm{L}$ IgG HRP (Thermo) was added for an additional hour before washing. Plates were developed with TMB Ultra (Thermo) and the reaction stopped by addition of equal volume $2 \mathrm{M} \mathrm{H}_{2} \mathrm{SO}_{4}$ after washing. Absorbance was read at $450 \mathrm{~nm}$.

Competition of soluble ACE2-huFc by $\mathrm{V}_{\mathrm{H}} \mathrm{H}$-huFc candidates identified from display screening was performed as follows. SARS-2 antigen was immobilized and blocked as described above. After blocking, serial dilutions of $\mathrm{V}_{\mathrm{H}} \mathrm{H}$-huFc antibodies were prepared in blocking solution and allowed to incubate for at least 2 hours, after which ACE2-rbFc was added to a final concentration of $0.1 \mu \mathrm{g} / \mathrm{mL}$ (SARS-CoV-1 S) or $0.06 \mu \mathrm{g} / \mathrm{mL}$ (SARS-2 S) and allowed to incubate for 1 hour with shaking at $25^{\circ} \mathrm{C}$. Plates were washed and 1:10,000 HRP-conjugated goat anti-rabbit IgG (Thermo) was added. Plates were developed as described above.

Differential Scanning Fluorimetry 
Thermostability for the $\mathrm{V}_{\mathrm{H}} \mathrm{H}$-huFc antibodies was determined by differential scanning fluorimetry (DSF). Each reaction contained $10 \mu \mathrm{g}$ of $\mathrm{V}_{\mathrm{H}} \mathrm{H}$-huFc in PBS with 10 $\mu \mathrm{M}$ SYPRO Orange (ThermoFisher). Reactions were heated from $10-95^{\circ} \mathrm{C}$ at a heating rate of $1^{\circ} \mathrm{C} / \mathrm{min}$ and monitored in the FRET channel of a BioRad CFX96. The melting

315 point for each of the $\mathrm{V}_{\mathrm{H}} \mathrm{H}$-huFc antibodies was calculated by the first derivative

316 method.(18)

317 Viruses and Cell Culture

Vero and Vero E6 cells (African green monkey kidney, ATCC CCL-81 and CRL1586, respectively) were maintained in culture medium supplemented with $10 \%$ fetal bovine serum (FBS), 100 units/ml penicillin, and $100 \mu \mathrm{g} / \mathrm{ml}$ streptomycin (Invitrogen), at $37{ }^{\circ} \mathrm{C}$ in $5 \% \mathrm{CO} 2$. For risk group (RG) 2 experiments and viral stocks, Vero cells were

322 cultured in supplemented minimum essential medium alpha (alpha MEM). For RG 3 323 experiments and viral stocks, Vero E6 cells were cultured in supplemented Dulbecco's 324 Modified Eagle's Medium (DMEM). A pseudotyped, replication-competent Vesicular 325 stomatitis virus (VSV) expressing eGFP as a marker of infection and the SARS-2 spike gene (VSV-SARS-2) in place of its own VSV-G gene was provided by Dr. Sean

327 Whelan(19, 20). Pseudotyped, single cycle VSV particles displaying the Severe acute 328 respiratory syndrome (SARS-1) spike protein (VSV-SARS-1-GFP) were derived from 329 recombinant VSV-DG-GFP in which the VSV-G envelope protein has been replaced with 330 GFP. VSV-SARS-1-GFP single cycle particles were produced in Expi293 cells through 331 transfection per manufacturer's instructions with the SARS-CoV-1 spike expression 332 plasmid (Sino Biological, Cat \#VG40150-G-N) containing a 19-aa deletion in the cytoplasmic tail. The Expi293 cells were subsequently infected with VSV-DG-GFP, itself 
pseudotyped with VSV-G, at $72 \mathrm{~h}$ post-transfection using a multiplicity of infection (MOI) of 3. The resulting VSV-SARS-1-GFP pseudotyped viruses were collected at $24 \mathrm{~h}$ postinfection. WT SARS-2 was deposited by the Centers for Disease Control and Prevention and obtained through BEI Resources, NIAID, NIH: SARS-Related Coronavirus 2, Isolate USA-WA1/2020, NR-52281. An infectious clone of SARS-2 expressing a NeonGreen reporter gene (icSARS-CoV-2-mNG, or SARS-2-NG) was provided by Dr. Pei Yong Shi.(21) Viral stocks were amplified in Vero E6 cells, supernatants were harvested upon extensive cytopathic effect, 48 (VSV-SARS-2-GFP) or 72 (SARS-2) hours post infection. Cellular debris was removed by centrifugation, and aliquots were stored at $-80^{\circ} \mathrm{C}$. Titers of viral stocks were determined by plaque assay. All work with WT SARS-2 was performed in Institutional Biosafety Committee approved BSL-3 and ABSL-3 facilities at Lawrence Livermore National Laboratory using appropriate personal protective equipment (PPE) and protective measures.

\section{SARS-2 Fluorescent Reporter Neutralization Assays}

Serial dilutions of $\mathrm{V}_{\mathrm{H}} \mathrm{H}$-huFc were prepared in supplemented media at $2 \mathrm{x}$ the desired final concentration. SARS-2-NG, VSV-SARS-2-GFP, or VSV-SARS-1-GFP was added to the serially diluted $\mathrm{V}_{\mathrm{H}} \mathrm{H}$-huFc antibodies for a final multiplicity of infection (MOI) of 0.2 (RG 2) or $0.1(R G 3)$ and allowed to incubate at $37^{\circ} \mathrm{C}$ for 30 minutes to 1 hour with shaking prior to transfer of virus- $\mathrm{V}_{\mathrm{H}} \mathrm{H}$-huFc mixture to cells seeded in 96 (RG 3) or 384 well plates (RG 2). $V_{H} H$-huFc-virus complexes were incubated with Vero cells at $37^{\circ} \mathrm{C}$ with $5 \% \mathrm{CO}_{2}$ for $12-16 \mathrm{~h}$. For RG 2 experiments, cells were subsequently fixed in $4 \%$ paraformaldehyde (Millipore Sigma) containing $10 \mathrm{mg} / \mathrm{mL}$ Hoechst 33342 nuclear stain (Invitrogen) for 30 min at room temperature, when fixative was replaced with PBS, and 
357 images were acquired with the Tecan Spark ${ }^{\circledR}$ Cyto multi-mode plate reader and image cytometer in both the DAPI and FITC channels to visualize nuclei and infected cells (i.e., eGFP-positive cells), respectively (4X objective, covering the entire well). Images were analyzed using the Spark Control Image Analyzer Software. For RG 3 experiments with, cells were lysed in RIPA buffer plus Halt protease inhibitor cocktail (ThermoFisher) and fluorescence was measured using $485 \mathrm{~nm}$ excitation and 528 emission wavelengths. Fluorescent values were background subtracted using no-infection controls and normalized to no-treatment infection values. The dose response curves and $50 \%$ effective inhibitory concentrations (EC $\left.\mathrm{E}_{50}\right)$ were generated using Graphpad Prism 9.

$\mathrm{V}_{\mathrm{H}} \mathrm{H}$-huFc-WT SARS-2 virus complexes were preincubated at $37^{\circ} \mathrm{C}$ with $5 \% \mathrm{CO}_{2}$ for 1 incubation of $\mathrm{V}_{\mathrm{H}} \mathrm{H}$-huFc-virus complexes with Vero $\mathrm{E} 6$ cells at $37^{\circ} \mathrm{C}$ with $5 \% \mathrm{CO}_{2}$,

FBS, 1\% P/S complemented 2X MEM were added. To stain, the MCC was aspirated, wells rinsed with PBS, and $0.4 \%$ crystal violet in $100 \%$ methanol was added for 10

373 minutes and then removed. Wells were then washed twice with water, and titers were

374 recorded in plaque forming units (PFU)/mL.

Affinity measurements for $\mathrm{V}_{\mathrm{H}} \mathrm{H}$-huFc antibodies were performed using biolayer interferometry (BLI) using an Octet 384 Red system (Sartorius). Measurements were conducted in $10 \mathrm{mM}$ phosphate (pH 7.4), $300 \mathrm{mM} \mathrm{NaCl}, 1 \mathrm{mg} / \mathrm{mL}$ BSA, 0.1\% NP-40.

$379 \mathrm{~V}_{\mathrm{H}} \mathrm{H}$-huFc ligands were immobilized on human Fc capturing sensors. WT and mutant 
SARS-2 RBD were used as the analyte and sensograms were fit to a global 1:1 fit.

Sensograms which deviated from a 1:1 global fit or fit well to a heterogeneous ligand model were designated as biphasic.

\section{Generation and Analysis of Escape Mutants} was generated in a similar fashion to that described in Baum et. al.(22) In brief, a series

to Vero cells and allowed to incubate for up to 72 hours until apparent cytopathic effect

(CPE) or widespread viral replication could be observed by GFP fluorescence.

Supernatant from wells containing the highest concentrations of $\mathrm{V}_{\mathrm{H}} \mathrm{H}$-huFc was collected diluted 500-fold and exposed to a series of higher concentrations of $\mathrm{V}_{\mathrm{H}} \mathrm{H}$-huFc antibodies for 1 hour at $37^{\circ} \mathrm{C}$ prior to addition to Vero cells. Cells were monitored for 60 hours for clear viral replication were collected and processed as mentioned above and viral RNA analyzed as described below.

VSV-SARS-2 genomic RNA was isolated for next-generation sequencing (NGS).

398 For library preparation, $25-100 \mathrm{ng}$ of total RNA was used to deplete rRNA using DNA 399 probes and RNase H provided in RiboErase (HMR) kit (Roche). The depleted RNA was 400 fragmented prior to cDNA synthesis followed by Illumina adaptor ligation using KAPA 401 RNA HyperPrep kit (Roche). The library was analyzed using High Sensitivity DNA 402 ScreenTape 1000 (Agilent) for quality and quantification and pulled together for the final 
403 library denaturation. Sequencing was performed on Illumina NextSeq 500/550 platform 404 with High Output v2.5 75-cycle mode. BCL files were converted to FASTQ and 405 demutiplexed using the bcl2fastq script from Mylllumina (https://my.illumina.com). The 406 quality filtering and adaptor trimming were performed using fastp with $-\mathrm{q} 30$ option. The 407 filtered reads were mapped to Spike protein coding region of the SARS-2 Wuhan Hu-1 408 isolate (GenBank:MN908947.3) using Bowtie 2.(23) The variant calling on the mapped 409 reads was performed using mpileup from Bcftools (https://samtools.github.io/bcftools/) and 410 inspected using Integrative Genomics Viewer (IGV).(24)

$411 \quad$ Animal Studies

All animal work was performed in accordance with protocols approved by the Lawrence Livermore National Laboratory Institutional Animal Care and Use Committee.

414 Groups of male and female K18-hACE2 C57BL/6J transgenic mice (Jackson Laboratory) 415 ranging in age from 12-16 weeks were inoculated intranasally with $2.5 \times 10^{4}$ PFU SARS-2 416 (USA-WA 01/2020) while under anesthesia (4-5\% isoflurane in $100 \%$ oxygen). Animals 417 were dosed prophylactically (-24 hours pre-infection) or therapeutically (+24 hours post418 infection) by intraperitoneal injection with $10 \mathrm{mg} / \mathrm{kg}$ of $\mathrm{V}_{\mathrm{H}} \mathrm{H}$-huFc or isotype control 419 antibody. Body weight was measured daily and any animal falling below $80 \%$ of their 420 starting weight was humanely euthanized in accordance with animal welfare guidelines.

$421 \quad$ Statistical analysis

Raw data for infection assays measured by reporter fluorescence were compared 423 using a two-tailed t test for each individual experiment. For plate assays, untreated, 424 infected controls and uninfected controls were included on every plate. Antibody-treated 425 cells that were infected were compared to control samples infected with the same virus. 
426 Kaplan-Meier survival curves were generated based on two independent experiments

427 and log rank tests were performed with Bonferroni multiple comparison correction applied

428 (GraphPad Prism). P values were considered significant when they were $<0.05\left(^{*}\right)$ and

429 very significant when they were $<0.01\left({ }^{* *}\right),<0.001\left({ }^{* * *}\right)$, or $<0.0001\left({ }^{* * *}\right)$.

$430 \quad$ Results

431 Library Construction

The $\mathrm{V}_{\mathrm{H}} \mathrm{H}$ library incorporated both the diversity and prevalence of amino acids at

key positions in each of the CDR1 and CDR2 derived from a database of 670 functional

$\mathrm{V}_{\mathrm{H}} \mathrm{H}$ antibodies (Fig. 1A).(15) For CDR3, full amino acid diversity and three different

based on the predominant lengths of these loops observed in the functional $\mathrm{V}_{\mathrm{H}} \mathrm{H}$

was synthetically produced and the observed prevalence of amino acids at each of the

In order to obtain sufficient diversity coverage for the library (i.e. transformants),

441150 electroporations were performed yielding approximately $3.38 \times 10^{10}$ transformants.

442 To determine the level of success for the ligation of the library into the vector backbone,

443 colony PCR was performed. Of the 408 colonies selected, 395 contained the correct size

444 amplified DNA fragment (95.9\%). This value was used to adjust the calculated value for

445 library diversity to $3.24 \times 10^{10}$. Finally, library diversity, quality, and the distribution of

446 CDR3 lengths were assessed by NGS from a total of $39,870,360$ reads (S1 and $\mathbf{S 2}$

447 Table). The 9-amino acid CDR3 was the most prevalent at $40 \%$, followed by 12 -amino 448 acid CDR3 at 34\%, and lastly the 15-amino acid CDR3 at 25\% of the observed diversity. 
449 Overall, there was good coverage of all represented CDR3s. Approximately $1 \%$ of 450 sequences contained a stop codon and $99 \%$ of reads were unique sequences

$451(38,592,027$ reads). Roughly $1 \%$ of reads were duplicates, and $0.01 \%(1,095$ sequences $)$

452 were present in triplicate. With these corrections the adjusted diversity for this nanobody

453 library is $3.18 \times 10^{10}$.

$454 \quad$ Panning against SARS-2 S and RBD

Four rounds of biopanning were used to identify clones that bind to the SARS-2 S

456 protein RBD. For the first three rounds, full-length soluble purified SARS-2 S protein was used, ensuring that conformational integrity of the RBD was maintained for initial selection. A 15 -minute heat denaturing step at $70^{\circ} \mathrm{C}$ was used to remove unstable sequences and a final round of biopanning against SARS-2 RBD was conducted to identify therapeutically relevant $\mathrm{V}_{\mathrm{H}} \mathrm{H}$ antibodies (Fig. 1B). Enrichment of phage against SARS-2 S was observed over the initial 3 rounds of biopanning (Fig. 1C and S3 Table) and there was a significant loss in phage recovered when the antigen was shifted to RBD (0.0005\% compared to $0.004 \%)$.

Polyclonal ELISA showed that over each round of biopanning there was enrichment for SARS-2 S binders. Interestingly, there was relatively little SARS-2 RBD 466 binding until panning was conducted against RBD specifically, indicating preferred 467 epitopes are outside the RBD (Fig. 1C). Additionally, neutralization of SARS-2 468 pseudotyped vesicular stomatitis virus encoding eGFP (VSV-SARS2-GFP)(19) was only observed after RBD biopanning (R4) showing enrichment for RBD binders is required to

470 remove clones binding to epitopes outside the RBD and to identify virus neutralizing 471 clones (Fig. 1D). Monoclonal characterization was performed using ELISA, 222 of the 
472384 clones were designated as hits. Clones that had $\mathrm{OD}_{450} \geq 2.5$ in the phage coat

473 monoclonal ELISA against both SARS-2 S and RBD and that did not bind BSA were

474 designated as hits (S2 Fig.). Of those designated as hits, 54 sequences were identified

475 as unique.

476 Evaluation of $\mathrm{V}_{\underline{H}} \underline{H-h u F c}$ Candidates

477 Humanized $\mathrm{V}_{\mathrm{H}} \mathrm{H}$ antibodies were produced as a fusion to the hinge region and 478 crystallizable fragment (Fc) domain of a human IgG1, which combines the advantages of 479 the $\mathrm{V}_{\mathrm{H}} \mathrm{H}$ with the improved half-life and effector functions of human IgG while reducing 480 the overall size by half that of a conventional antibody(12). All 54 unique $\mathrm{V}_{\mathrm{H}} \mathrm{H}$ sequences were commercially produced in a $\mathrm{V}_{\mathrm{H}} \mathrm{H}-$ huFc (hulgG1 Fc) format by GenScript for further 482 characterization and triage (Fig. 2A). Of the $54 \mathrm{~V}_{\mathrm{H}} \mathrm{H}-$ huFc antibodies, 49 showed positive 483 binding to both SARS-2 S and RBD with little to no binding to BSA by ELISA (S3 Fig). 484 Those which showed positive binding by ELISA were then tested for their ability to 485 compete with ACE2-huFc for binding to SARS-2 S by a competition ELISA (S4 Table).

486 Finally, 46 candidates were evaluated for their ability to neutralize VSV-SARS-2-GFP 487 infection in vitro, with $34 \mathrm{~V}_{\mathrm{H}} \mathrm{H}$-huFc antibodies demonstrating full or partial neutralization of infection (S4 Table).

For reconfirmation of binding and neutralization, $16 \mathrm{~V}_{\mathrm{H}} \mathrm{H}-\mathrm{huFc}$ antibodies were selected based on low $50 \%$ effective inhibitory concentration $\left(\mathrm{EC}_{50}\right)$ values and were 491 produced and purified in-house (S4 Fig). None of these candidates inhibited infection with pseudotyped, single cycle VSV particles displaying the SARS-1 S protein (VSV-SARS-1antibodies, SP1B4, SP1D9, and SP3H4, were identified as showing the greatest potency 
495 in viral neutralization with $\mathrm{EC}_{50} \mathrm{~s}$ of $0.33,0.45$, and $0.14 \mathrm{nM}$ respectively, against VSVSARS-2-GFP and $\mathrm{EC}_{50}$ s of 3.14, 1.12, and $0.70 \mathrm{nM}$ respectively, against WT SARS-2 by three independent virus-based assays (S5 Table), suggesting that SP1B4, SP1D9, and SP3H4 are potent neutralizers of SARS-2, and this observed potency correlates with their stability of $\mathrm{V}_{\mathrm{H}} \mathrm{H}$-huFc antibodies was evaluated by differential scanning fluorimetry (DSF). Melting temperatures for SP1B4, SP1D9, and SP3H4 were $60.4^{\circ} \mathrm{C}, 64.0^{\circ} \mathrm{C}$, and $61.0^{\circ} \mathrm{C}$ respectively and are comparable to previously reported SARS-2 neutralizing $\mathrm{V}_{\mathrm{H}} \mathrm{H}$-huFc antibodies (Fig. 2J; S5 Fig.).(25)

Dissociation constants were determined for the $\mathrm{V}_{\mathrm{H}} \mathrm{H}$-huFc antibodies using association and dissociation kinetics which could not be reconciled with a 1:1 global fit analysis and it was therefore not given kinetic parameters (Fig. 2I).

510 Epitope Mapping by Escape Mutant Formation and BLI

512 mutants generated in the presence of SP1B4, SP1D9, or SP3H4, followed by 513 confirmation with BLI binding studies of escape mutant SARS-2 RBDs (Fig. 3). Within 48-

51460 hours of the first passage, viral escape was apparent from all $\mathrm{V}_{\mathrm{H}} \mathrm{H}$-huFc antibodies at 515 the highest concentration tested, with all cells expressing GFP. The viral supernatant 516 used for the second passage was completely resistant to neutralization from a 15-fold 517 excess of the corresponding $\mathrm{V}_{\mathrm{H}} \mathrm{H}$-huFc (Fig. 3C). Escape mutations were characterized 
by RNAseq for each of the VSV-SARS-2-GFP supernatants (Fig. 3D). Interestingly, for SP1B4 and SP1D9, E484K (the mutation found in the variant B.1.351 first isolated in South Africa) seems to be selected against in the second passage and Q493R and S494P seem to stabilize as the predominant mutations observed (Fig. 3D). This may indicate these two $\mathrm{V}_{\mathrm{H}} \mathrm{H}$-huFc antibodies have similar binding modes. For SP3H4, the L452R mutation seems to be the predominant mutant observed, with none of the virus showing any of the same mutations observed for SP1B4 and SP1D9. This may indicate that this $\mathrm{V}_{\mathrm{H}} \mathrm{H}$-huFc engages the RBD region differently. The $L 452 \mathrm{R}$ mutation is the predominant mutation found in the recently described variants CAL.20A, derived from clade 20A (lineage B.1.232,) and CAL.20C, derived from clade 20C (lineage B.1.429), that are associated with multiple outbreaks in California.(26-28) human ACE2 and the three $\mathrm{V}_{\mathrm{H}} \mathrm{H}$-huFc antibodies was determined by $\mathrm{BLI}$ (S6-9 Fig. and S6 Table). In all cases, individual mutations were shown to have little to no impact on ACE2 binding, suggesting minimal impact on viral infection. Mutations in the RBD significantly impacted $\mathrm{V}_{\mathrm{H}} \mathrm{H}$-huFc binding. Interestingly, SP3H4 maintained the ability to bind to L452R despite this being the predominant mutation observed in the escape mutant

535 VSV-SARS-2-GFP virus generated. Additionally, BLI results show 1:1 binding kinetics for SP3H4 binding to the L452R mutant RBD. The biphasic kinetics observed with SP3H4

537 and WT RBD combined with the 1:1 binding kinetics of SP3H4 for RBD with the L452R mutation may indicate that SP3H4 has multiple binding sites. SP1D9 maintained the ability to bind many of the point mutations generated, though binding was abrogated by 
Q493R and S494P (Fig. 3D) as expected based on the escape mutant analysis. All mutations generated in RBD abrogated binding by SP1B4.

Next, SARS-2 RBDs from recently identified and circulating SARS-2 variants

Table). The B.1.1.7 variant RBD showed an $\sim 5$-fold increased affinity to the ACE2 receptor $\left(K_{D}=2.5 \mathrm{nM}\right.$ vs $13.3 \mathrm{nM}$ for $\left.W T\right)$. While SP1B4 $\left(\mathrm{K}_{\mathrm{D}}=97.7 \mathrm{nM}\right)$ and SP1D9 $\left(\mathrm{K}_{\mathrm{D}}\right.$

$547=49.7 \mathrm{nM}$ ) maintained binding affinity for the B.1.1.7 RBD, there was a 2.5 -fold and 5.5 548 -fold decrease in affinity in comparison to the Wuhan RBD $\left(\mathrm{K}_{\mathrm{D}}=39.5 \mathrm{nM}\right.$, and $8.9 \mathrm{nM}$ respectively, (S7-8 Fig.) and a visible difference in binding to this RBD for SP3H4 (S9

Fig.). For the SARS-2 RBD from the B.1.351 variant, the $\mathrm{K}_{\mathrm{D}}$ for $A C E 2$ was similar to the

$551 K_{D}$ for the Wuhan strain but there was no detectable binding for SP1B4, SP1D9 or SP3H4

552 (S7-9 Fig.).

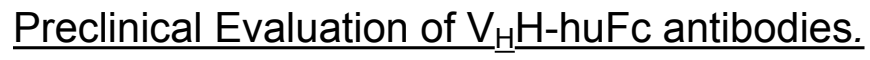

554 Top performing $\mathrm{V}_{\mathrm{H}} \mathrm{H}$-huFc antibodies SP1B4, SP1D9 and SP3H4, were assessed for in vivo prophylactic (-24 hours) and therapeutic (+24 hours) efficacy against fully virulent WT SARS-2 using the recently described K18-hACE2 transgenic mouse model of SARS-

5572 infection.(29) Two of the three $\mathrm{V}_{\mathrm{H}} \mathrm{H}$-huFc antibodies tested, SP1D9 and SP3H4, 558 provided very significant protection $(p<0.0001)$ over the isotype control in

559 prophylactically dosed mice. Although SP1B4 was a potent neutralizer in vitro it did not 560 demonstrate efficacy against challenge with SARS-2 in vivo (Fig. 4A and 4B) and was 561 not pursued in further in vivo studies. This result highlights the importance of animal 562 validation studies to triage top candidates for clinical evaluation. The SP1D9 group 
showed $94 \%$ survival $(n=16)$, and the SP3H4 group showed $87.5 \%$ survival $(n=16)$ at ten days post infection, indicating effective neutralizing activity in vivo (Fig. 4A). While 81.3\% $(n=16)$ of control treated mice lost more than $20 \%$ of their starting weight by 6 days post infection (dpi), requiring euthanasia, those pretreated with SP1D9 lost an average of only $3.9 \%(+/-4.8 \%)$ of their starting weight (Fig. 4B and S10 Fig.). Similarly, the SP3H4 dosed group exhibited a $5.4 \%$ average (+/-9.3\%) weight loss. Animals dosed prophylactically with the poorest performing $\mathrm{V}_{\mathrm{H}} \mathrm{H}$-huFc, SP1B4, lost an average of $17.7 \%(+/-8.3 \%)$ of their starting weight, with $50 \%$ of animals succumbing to infection by 6 dpi (Fig. 4B \& S10 Fig.).

Since SARS-2 viral titers peak as early as 48 hours post-infection (hpi) in vivo, allowing the virus to establish infection for 24 hours prior to therapeutic administration should demonstrate the versatility of these $\mathrm{V}_{\mathrm{H}} \mathrm{H}$-huFc antibodies in disease treatment.(29) To evaluate the efficacy of SP1D9 and SP3H4 $\mathrm{V}_{\mathrm{H}} \mathrm{H}$-huFc antibodies post-exposure, mice were infected intranasally with $2.5 \times 10^{4} \mathrm{PFU}$ SARS-2, then administered $10 \mathrm{mg} / \mathrm{kg}$ of $\mathrm{V}_{\mathrm{H}} \mathrm{H}$ huFc antibodies 24 hpi. Impressively, both SP1D9 and SP3H4 demonstrated significant therapeutic protection ( $p=0.0033, p=0.0013$, respectively) over that of the isotype control. The SP1D9 group showed $58 \%$ survival $(n=8)$, and the SP3H4 group showed $75 \%$ survival $(n=8)$ at ten dpi (Fig. 4C). Of note, several surviving individuals in each of the post-exposure $\mathrm{V}_{\mathrm{H}} \mathrm{H}$-huFc-treated groups exhibited $10-15 \%$ weight loss up to 5 dpi, but then rebounded from 6-10 dpi, gaining back 90-95\% of their starting weight (Fig. 4D and S10 Fig.). Taken together, these data demonstrate protection from lethal infection after a single $10 \mathrm{mg} / \mathrm{kg}$ dose, and further suggest that neutralization of SARS-2 by $\mathrm{V}_{\mathrm{H}} \mathrm{H}$ huFc antibodies in vivo can promote recovery from an ongoing infection. 


\section{Discussion}

The COVID-19 pandemic caused by SARS-2 has resulted in 146 million cases with 3.09 million deaths and an estimated global economic cost of over 10.3 trillion dollars in forgone output for 2020 and 2021.(30) As variants of SARS-2 emerge, it is essential to possess a diverse set of prophylactic and therapeutic tools, in order to maintain the progress made toward ending this pandemic. While vaccines have been great successes, therapeutic biologics are emerging as a critical tool in preventing progression to severe disease in those who do become infected.(31)

Several therapeutic antibody candidates with efficacy against SARS-2 have been recently identified, including three with emergency use authorization, but there are a number of caveats associated with conventional antibodies as therapeutics such as timeconsuming discovery, relying on immunized or patient sera, expensive and laborintensive production, and the large doses required to achieve clinical efficacy. $(9,22,32-$ 34) High stability, solubility, and the ability to be multimerized, are just some of the many reasons why single-domain heavy chain-based antibody therapeutics $\left(\mathrm{V}_{\mathrm{H}} \mathrm{H}-\mathrm{Fc}\right)$ represent a highly promising method for treatment.(12) One $\mathrm{V}_{\mathrm{H}} \mathrm{H}$-based therapeutic is already approved by the FDA for treatment of a rare blood clotting disorder and many more are in late stage clinical trials. $(12,35)$ The small size of $\mathrm{V}_{\mathrm{H}} \mathrm{H}$ antibodies and the wider distribution of CDR3 loop lengths compared to human IgGs expands the type of epitope which can be effectively targeted.(12) Finally, preliminary evidence suggests that $\mathrm{V}_{\mathrm{H}} \mathrm{H}-\mathrm{Fc}$ antibodies are transported more efficiently into the blood and lung parenchyma following intraperitoneal administration compared to conventional IgG1 antibodies.(36, 37) Several groups have recently used in vitro screening techniques to identify $\mathrm{V}_{\mathrm{H}} \mathrm{H}$ domains with high 
affinity for the SARS-2 S protein and neutralization of SARS-2 with $\mathrm{EC}_{50} \mathrm{~S}$ ranging from $0.02 \mathrm{nM}$ to $2 \mu \mathrm{M}$ in pseudotyped virus and in $W T$ SARS-2 virus assays.(35, 38-45) However, in addition to neutralization, there are several antibody and immune functions that contribute to prophylactic and therapeutic effectiveness in vivo, and only one of these studies characterized the in vivo efficacy of a single $\mathrm{V}_{\mathrm{H}} \mathrm{H}-\mathrm{Fc}$ construct $\left(\mathrm{V}_{\mathrm{H}} \mathrm{H}-\mathrm{Fc}\right.$ ab8) at reducing lung viral titers at 2 or 5 days post infection.(36) Importantly, the mouse-adapted SARS-2 and the golden hamster SARS-2 infection models used in this study are not lethal, rather, they inform efficacy for more mild disease cases. $(29,36,46,47)$ In this regard, the K18-hACE2 SARS-2 infection model is particularly valuable for testing the protective and therapeutic properties of novel antibodies in the context of severe infection and disease. $(48,49)$

In this study, we have identified and characterized several prospective therapeutic neutralizing nanobodies $\left(\mathrm{V}_{\mathrm{H}} \mathrm{Hs}\right)$ both in vitro and in vivo from a high diversity synthetic library. Three candidate $\mathrm{V}_{\mathrm{H}} \mathrm{H}$-huFc antibodies are highlighted in this study because of their potent sub-nanomolar $\mathrm{EC}_{50} \mathrm{~S}$ in preventing viral infection. For the SP1B4, SP1D9, and $\mathrm{SP} 3 \mathrm{H} 4$ huFc constructs, affinity maturation was not required to achieve potent neutralization against SARS-2 pseudovirus $\left(E_{50} \mathrm{~S}\right.$ of $0.33,0.45$, and $0.14 \mathrm{nM}$, respectively) or WT SARS-2 virus ( $\mathrm{EC}_{50} \mathrm{~S}$ of $3.14,1.12$ and $0.70 \mathrm{nM}$, respectively).

Two of the $\mathrm{V}_{\mathrm{H}} \mathrm{H}$-huFc antibodies provided protection of K18-hACE2 transgenic mice when administered 24 hours before infection with WT SARS-2. A single dose of SP1D9 or SP3H4 exhibited significant therapeutic value when administered a full $24 \mathrm{hpi}$, which is closer to the peak of infection than was used to evaluate therapeutic efficacy of $\mathrm{V}_{\mathrm{H}} \mathrm{H}$ Fc ab8 $(6 \mathrm{hpi}) .(36,48)$ In the present study, the onset of weight loss at $2-4 \mathrm{dpi}$, indicative 
632 of effective disease progression, and subsequent improvement after treatment establishes the potential for efficacy in the presence of an established SARS-2 infection

637 this one, have generated mutations in vitro that exist in circulating SARS-2 variants and revealed that these mutations partially or completely block binding of top anti-SARS-2 therapeutic antibodies.(50) The potential for continued mutation acquisition and escape in SARS-2 highlights the critical importance of having multiple options for antibody cocktails.(39) Furthermore, sequencing analysis of the latest strains' mutation status would allow patient stratification to identify which therapeutic regimen will be most effective in combating the latest emerging variant.(39)

In this study, viral escape was readily apparent in the presence of our top candidates, with several mutations in the RBD. Interestingly, many of the initial mutations were selected against in the second passage (Fig. 3) and none of these individual mutations in the RBD significantly impacted binding to ACE2 (Fig. 3D and S6 Fig.). This suggests that these positions of the $S$ gene are highly susceptible to single-nucleotide 649 polymorphisms and should be considered when identifying future preclinical antibody candidates as they may be present in future variant strains. Escape mutations observed

651 for our two most promising candidates are all found in proximity to each other likely 652 indicating overlapping epitopes, though they may engage this epitope with different 653 geometries (Fig. 3). All three $\mathrm{V}_{\mathrm{H}} \mathrm{H}$ antibodies neutralize viral infection by targeting the 654 RBD of the SARS-2 S protein and compete directly with ACE2 binding to trimeric SARS-2 
$655 \mathrm{~S}$ which indicates they are class I nanobodies.(35) Although the $\mathrm{V}_{\mathrm{H}} \mathrm{H}$ antibodies described

656 in this study bind to a single epitope, other groups have recently identified $\mathrm{V}_{\mathrm{H}} \mathrm{H}$ antibodies

657 that target a distinct epitope and could be used in combination with the $\mathrm{V}_{\mathrm{H}} \mathrm{H}$ antibodies

658 identified in this study to develop highly potent therapeutic cocktails that prevent the 659 emergence of escape mutants.(39, 41, 45)

We have also evaluated our $\mathrm{V}_{\mathrm{H}} \mathrm{H}$-huFc antibodies' ability to engage clinically relevant SARS-2 variants (B.1.1.7 and B.1.351) which pose a significant hurdle to

662 therapeutic efficacy and vaccine-derived immunity. Interestingly, we observed a $\sim 5$-fold 663 increase in affinity of the B.1.1.7 variant RBD for the ACE2 receptor, which may account 664 for the increased infectivity observed with this strain of SARS-2. While none of our most 665 promising candidates bind to the B.1.351 variant, SP1D9 and SP3H4 maintained binding 666 affinity to the B.1.1.7 RBD variant (S8-9 Fig.). The E484K mutation, observed in the 667 B.1.351 variant and now a new variant B.1.526, confers total abrogation of $\mathrm{V}_{\mathrm{H}} \mathrm{H}-\mathrm{huFc}$ 668 binding. Another clinically relevant mutation, L452R, which can be found in circulating variant strains CAL.20A and CAL.20C, was selected for with SP3H4. Interestingly, SP3H4 retains affinity for SARS-2 RBD with the L452R mutations. Furthermore, the kinetics

671 appear to shift from biphasic to $1: 1$ with the L452R mutation, which may indicate that 672 SP3H4 has two non-overlapping binding sites. While many of the mutations in clinically 673 relevant SARS-2 variants emerged in this study, there are several mutations that arose 674 in this study which have yet to be highlighted. Using these antibodies to rapidly generate 675 escape mutants could help to preemptively identify and develop countermeasures for 676 future variants before they arise and circulate in the population. 
In this work we have reported the design of a large synthetic $\mathrm{V}_{\mathrm{H}} \mathrm{H}$ library $(3.18 \mathrm{x}$ $10^{10}$ ) and described the library's utility in identifying over $50 \mathrm{~V}_{\mathrm{H}} \mathrm{H}$ candidates which bind

to SARS-2. We triaged top candidates based on neutralization efficiency in vitro, and evaluated efficacy in vivo using a mouse model of severe SARS-2 disease. To our knowledge, this is the first study to examine survival up to ten dpi with a single dose of $\mathrm{V}_{\mathrm{H}} \mathrm{H}-\mathrm{Fc}$ given $24 \mathrm{hpi}$ in the context of a lethal SARS-2 infection. While in vitro neutralization assays and short-range in vivo titer reduction studies are informative, they do not always recapitulate likelihood of survival. There are several reasons why in vitro potency may not correlate with in vivo protection, including an antibody's pharmacokinetic properties and/or a broad range of immunomodulatory functions required for viral clearance.(49,51-53). Studies are currently underway to evaluate the efficacy of $\mathrm{V}_{\mathrm{H}} \mathrm{H}$ huFc combinations administered at later time points post-infection and to investigate the

689 role of Fc effector function in protection against SARS-2. The demonstrated ability of this virus to generate escape mutants emphasizes the need for multiple therapeutic options, with demonstrated in vivo activity in a post-infection context, to rapidly react to the emergence of resistant variants as expanded vaccine and antibody therapy use creates selection pressures on the viral population.

694 Conflicts of interest

695 No conflicts of interest to declare.

\section{Acknowledgements}

697 We would like to thank Prof. Sean Whelan from Washington University School of

698 Medicine St. Louis for graciously providing access to the pseudotyped VSV-SARS-GFP virus used in this study. We would also like to thank Dr. Pei Yong Shi from the World 
Reference Center for Emerging Viruses and Arboviruses at University of Texas, Medical

701

702

703

704

705

706

707

708

709

710

711

712

713

714

715

716

717

718

719

720

721

722

723

724

725

726

727

728

Branch for generously providing the infectious clone of SARS-CoV-2 expressing a

NeonGreen reporter gene. We would also like to thank Robert Meager for critically

reviewing the paper. This work was supported by the Laboratory Directed Research and

Development Program at Sandia National Laboratories and the Department of Energy

(DOE) Office of Science through the National Virtual Biotechnology Laboratory, a

consortium of DOE national laboratories focused on response to COVID-19, with

funding provided by the Coronavirus CARES Act. Sandia National Laboratories is a

multi-mission laboratory managed and operated by National Technology \& Engineering

Solutions of Sandia, LLC, a wholly owned subsidiary of Honeywell International Inc., for

the U.S. Department of Energy's National Nuclear Security Administration under

contract DE-NA0003525. This paper describes objective technical results and analysis.

Any subjective views or opinions that might be expressed in the paper do not

necessarily represent the views of the U.S. Department of Energy or the United States

Government. All work performed at Lawrence Livermore National Laboratory is

performed under the auspices of the U.S. Department of Energy under Contract DE-

AC52-07NA27344.

\section{References}

1. Dong E, Du H, Gardner L. An interactive web-based dashboard to track COVID-19 in real time. Lancet Infect Dis. 2020;20(5):533-4.

2. Yimer B, Ashebir W, Wolde A, Teshome M. COVID-19 and Global Health Security: Overview of the Global Health Security Alliance, COVID-19 Response, African Countries' Approaches, and Ethics. Disaster Med Public Health Prep. 2020:1-5.

3. Katz LM. (A Little) Clarity on Convalescent Plasma for Covid-19. N Engl J Med. 2021;384(7):666-8. 4. Ali MG, Zhang Z, Gao Q, Pan M, Rowan EG, Zhang J. Recent advances in therapeutic applications of neutralizing antibodies for virus infections: an overview. Immunol Res. 2020;68(6):325-39. 
5. Jiang S, Zhang X, Yang Y, Hotez PJ, Du L. Neutralizing antibodies for the treatment of COVID-19. Nat Biomed Eng. 2020;4(12):1134-9.

6. Ryman JT, Meibohm B. Pharmacokinetics of Monoclonal Antibodies. CPT Pharmacometrics Syst Pharmacol. 2017;6(9):576-88.

7. Zost SJ, Gilchuk P, Case JB, Binshtein E, Chen RE, Nkolola JP, et al. Potently neutralizing and protective human antibodies against SARS-CoV-2. Nature. 2020;584(7821):443-9.

8. Weinreich DM, Sivapalasingam S, Norton T, Ali S, Gao H, Bhore R, et al. REGN-COV2, a Neutralizing Antibody Cocktail, in Outpatients with Covid-19. N Engl J Med. 2021;384(3):238-51.

9. Chen P, Nirula A, Heller B, Gottlieb RL, Boscia J, Morris J, et al. SARS-CoV-2 Neutralizing Antibody LY-CoV555 in Outpatients with Covid-19. N Engl J Med. 2021;384(3):229-37.

10. Mitchell LS, Colwell LJ. Comparative analysis of nanobody sequence and structure data. Proteins. 2018;86(7):697-706.

11. Harmsen MM, De Haard HJ. Properties, production, and applications of camelid single-domain antibody fragments. Appl Microbiol Biotechnol. 2007;77(1):13-22.

12. Bannas P, Hambach J, Koch-Nolte F. Nanobodies and Nanobody-Based Human Heavy Chain Antibodies As Antitumor Therapeutics. Frontiers in immunology. 2017;8:1603-.

13. Grant OC, Montgomery D, Ito K, Woods RJ. Analysis of the SARS-CoV-2 spike protein glycan shield reveals implications for immune recognition. Sci Rep. 2020;10(1):14991.

14. Wrapp D, Wang N, Corbett KS, Goldsmith JA, Hsieh CL, Abiona O, et al. Cryo-EM structure of the 2019-nCoV spike in the prefusion conformation. Science. 2020;367(6483):1260-3.

15. Wilton EE, Opyr MP, Kailasam S, Kothe RF, Wieden HJ. sdAb-DB: The Single Domain Antibody Database. ACS Synth Biol. 2018;7(11):2480-4.

16. Moutel S, Bery N, Bernard V, Keller L, Lemesre E, de Marco A, et al. NaLi-H1: A universal synthetic library of humanized nanobodies providing highly functional antibodies and intrabodies. Elife. 2016;5.

17. Chen S, Zhou Y, Chen Y, Gu J. fastp: an ultra-fast all-in-one FASTQ preprocessor. Bioinformatics. 2018;34(17):i884-i90.

18. Niesen $\mathrm{FH}$, Berglund $\mathrm{H}$, Vedadi $\mathrm{M}$. The use of differential scanning fluorimetry to detect ligand interactions that promote protein stability. Nat Protoc. 2007;2(9):2212-21.

19. Case JB, Rothlauf PW, Chen RE, Liu Z, Zhao H, Kim AS, et al. Neutralizing antibody and soluble ACE2 inhibition of a replication-competent VSV-SARS-CoV-2 and a clinical isolate of SARS-CoV-2. bioRxiv. 2020:2020.05.18.102038.

20. Case JB, Rothlauf PW, Chen RE, Liu Z, Zhao H, Kim AS, et al. Neutralizing Antibody and Soluble ACE2 Inhibition of a Replication-Competent VSV-SARS-CoV-2 and a Clinical Isolate of SARS-CoV-2. Cell host \& microbe. 2020;28(3):475-85.e5.

21. Xie X, Muruato A, Lokugamage KG, Narayanan K, Zhang X, Zou J, et al. An Infectious cDNA Clone of SARS-CoV-2. Cell Host Microbe. 2020;27(5):841-8.e3.

22. Baum A, Fulton BO, Wloga E, Copin R, Pascal KE, Russo V, et al. Antibody cocktail to SARS-CoV-2 spike protein prevents rapid mutational escape seen with individual antibodies. Science. 2020;369(6506):1014-8.

23. Langmead B, Salzberg SL. Fast gapped-read alignment with Bowtie 2. Nat Methods. 2012;9(4):357-9.

24. Robinson JT, Thorvaldsdóttir H, Wenger AM, Zehir A, Mesirov JP. Variant Review with the Integrative Genomics Viewer. Cancer Res. 2017;77(21):e31-e4.

25. Dong J, Huang B, Wang B, Titong A, Gallolu Kankanamalage S, Jia Z, et al. Development of humanized tri-specific nanobodies with potent neutralization for SARS-CoV-2. Sci Rep.

2020;10(1):17806. 
26. Tchesnokova V, Kulakesara H, Larson L, Bowers V, Rechkina E, Kisiela D, et al. Acquisition of the L452R mutation in the ACE2-binding interface of Spike protein triggers recent massive expansion of SARS-Cov-2 variants. bioRxiv. 2021:2021.02.22.432189.

27. Zhang W, Davis BD, Chen SS, Sincuir Martinez JM, Plummer JT, Vail E. Emergence of a Novel SARS-CoV-2 Variant in Southern California. JAMA. 2021.

28. Deng X, Garcia-Knight MA, Khalid MM, Servellita V, Wang C, Morris MK, et al. Transmission, infectivity, and antibody neutralization of an emerging SARS-CoV-2 variant in California carrying a L452R spike protein mutation. medRxiv. 2021:2021.03.07.21252647.

29. Winkler ES, Bailey AL, Kafai NM, Nair S, McCune BT, Yu J, et al. SARS-CoV-2 infection of human ACE2-transgenic mice causes severe lung inflammation and impaired function. Nat Immunol. 2020;21(11):1327-35.

30. What is the economic cost of covid-19? The Economist. 2021 January 7, 2021.

31. FDA authorizes revisions to fact sheets to address SARS-CoV-2 variants for monoclonal antibody products under emergency use authorization [press release]. U.S. Food \& Drug Administration, 03/10/2021 2021.

32. Chames $P$, Van Regenmortel M, Weiss E, Baty D. Therapeutic antibodies: successes, limitations and hopes for the future. British Journal of Pharmacology. 2009;157(2):220-33.

33. Dhama K, Sharun K, Tiwari R, Dadar M, Malik YS, Singh KP, et al. COVID-19, an emerging coronavirus infection: advances and prospects in designing and developing vaccines, immunotherapeutics, and therapeutics. Hum Vaccin Immunother. 2020;16(6):1232-8.

34. Ju B, Zhang $Q$, Ge X, Wang R, Yu J, Shan S, et al. Potent human neutralizing antibodies elicited by SARS-CoV-2 infection. bioRxiv. 2020:2020.03.21.990770.

35. Schoof M, Faust B, Saunders RA, Sangwan S, Rezelj V, Hoppe N, et al. An ultrapotent synthetic nanobody neutralizes SARS-CoV-2 by stabilizing inactive Spike. Science. 2020;370(6523):1473-9.

36. Li W, Schäfer A, Kulkarni SS, Liu X, Martinez DR, Chen C, et al. High Potency of a Bivalent Human $\mathrm{V}(\mathrm{H})$ Domain in SARS-CoV-2 Animal Models. Cell. 2020;183(2):429-41.e16.

37. Wesolowski J, Alzogaray V, Reyelt J, Unger M, Juarez K, Urrutia M, et al. Single domain antibodies: promising experimental and therapeutic tools in infection and immunity. Med Microbiol Immunol. 2009;198(3):157-74.

38. Huo J, Le Bas A, Ruza RR, Duyvesteyn HME, Mikolajek H, Malinauskas T, et al. Neutralizing nanobodies bind SARS-CoV-2 spike RBD and block interaction with ACE2. Nature Structural \& Molecular Biology. 2020;27(9):846-54.

39. Koenig P-A, Das H, Liu H, Kümmerer BM, Gohr FN, Jenster L-M, et al. Structure-guided multivalent nanobodies block SARS-CoV-2 infection and suppress mutational escape. Science. 2021;371(6530):eabe6230.

40. Wrapp D, De Vlieger D, Corbett KS, Torres GM, Wang N, Van Breedam W, et al. Structural Basis for Potent Neutralization of Betacoronaviruses by Single-Domain Camelid Antibodies. Cell. 2020;181(5):1004-15.e15.

41. Bracken CJ, Lim SA, Solomon P, Rettko NJ, Nguyen DP, Zha BS, et al. Bi-paratopic and multivalent VH domains block ACE2 binding and neutralize SARS-CoV-2. Nat Chem Biol. 2021;17(1):113-21.

42. Sun Z, Chen C, Li W, Martinez DR, Drelich A, Baek DS, et al. Potent neutralization of SARS-CoV-2 by human antibody heavy-chain variable domains isolated from a large library with a new stable scaffold. MAbs. 2020;12(1):1778435.

43. Li W, Schäfer A, Kulkarni SS, Liu X, Martinez DR, Chen C, et al. High Potency of a Bivalent Human VH Domain in SARS-CoV-2 Animal Models. Cell. 2020;183(2):429-41.e16.

44. Lu Q, Zhang Z, Li H, Zhong K, Zhao Q, Wang Z, et al. Development of multivalent nanobodies blocking SARS-CoV-2 infection by targeting RBD of spike protein. Journal of Nanobiotechnology. 2021;19(1):33. 
824 45. Xiang Y, Nambulli S, Xiao Z, Liu H, Sang Z, Duprex WP, et al. Versatile and multivalent nanobodies efficiently neutralize SARS-CoV-2. Science. 2020;370(6523):1479-84.

826 46. Sia SF, Yan L-M, Chin AWH, Fung K, Choy K-T, Wong AYL, et al. Pathogenesis and transmission of 827 SARS-CoV-2 in golden hamsters. Nature. 2020;583(7818):834-8.

828 47. Dinnon KH, 3rd, Leist SR, Schäfer A, Edwards CE, Martinez DR, Montgomery SA, et al. A mouse829 adapted model of SARS-CoV-2 to test COVID-19 countermeasures. Nature. 2020;586(7830):560-6.

830 48. Rosenfeld R, Noy-Porat T, Mechaly A, Makdasi E, Levy Y, Alcalay R, et al. Post-exposure 831 protection of SARS-CoV-2 lethal infected K18-hACE2 transgenic mice by neutralizing human monoclonal 832 antibody. Nature Communications. 2021;12(1):944.

833 49. Winkler ES, Gilchuk P, Yu J, Bailey AL, Chen RE, Chong Z, et al. Human neutralizing antibodies against SARS-CoV-2 require intact Fc effector functions for optimal therapeutic protection. Cell.

835 2021;184(7):1804-20.e16.

836 50. Zhou D, Dejnirattisai W, Supasa P, Liu C, Mentzer AJ, Ginn HM, et al. Evidence of escape of SARS837 CoV-2 variant B.1.351 from natural and vaccine induced sera. Cell. 2021.

838 51. Schäfer A, Muecksch F, Lorenzi JCC, Leist SR, Cipolla M, Bournazos S, et al. Antibody potency, 839 effector function, and combinations in protection and therapy for SARS-CoV-2 infection in vivo. Journal 840 of Experimental Medicine. 2020;218(3).

841 52. Liu R, Oldham RJ, Teal E, Beers SA, Cragg MS. Fc-Engineering for Modulated Effector Functions842 Improving Antibodies for Cancer Treatment. Antibodies. 2020;9(4):64.

843 53. van Erp EA, Luytjes W, Ferwerda G, van Kasteren PB. Fc-Mediated Antibody Effector Functions

844 During Respiratory Syncytial Virus Infection and Disease. Frontiers in Immunology. 2019;10(548).

845

846 
A.

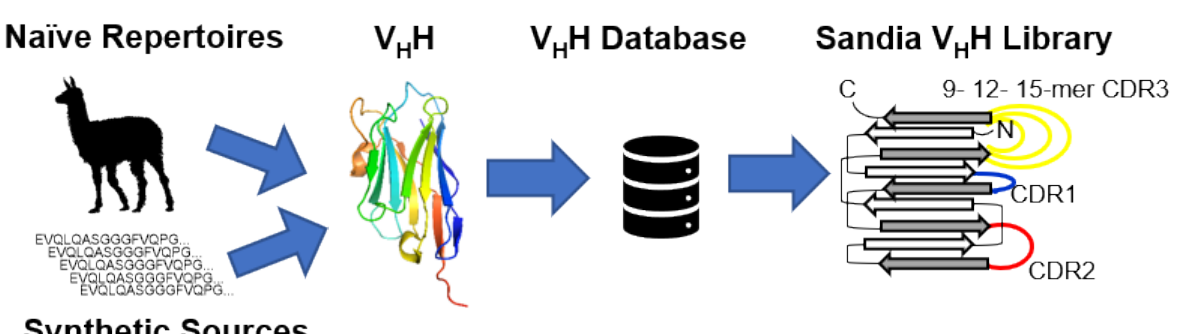

Synthetic Sources

B.

Full SARS-CoV-2 S SARS-CoV-2 RBD
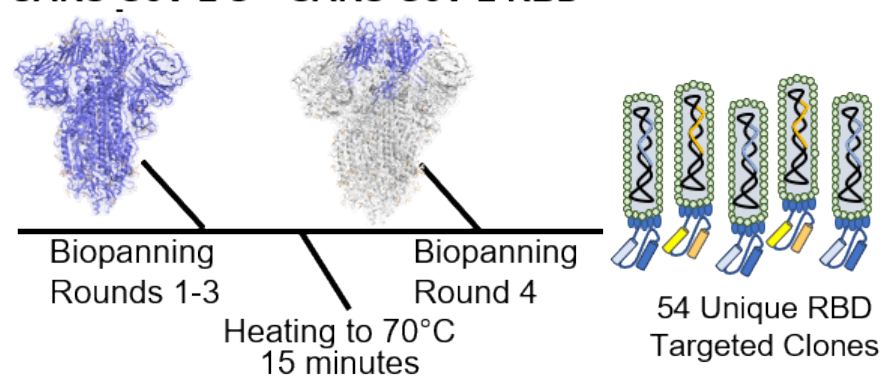

D. Enriched Phage Neutralization of VSV-SARS-2-GFP

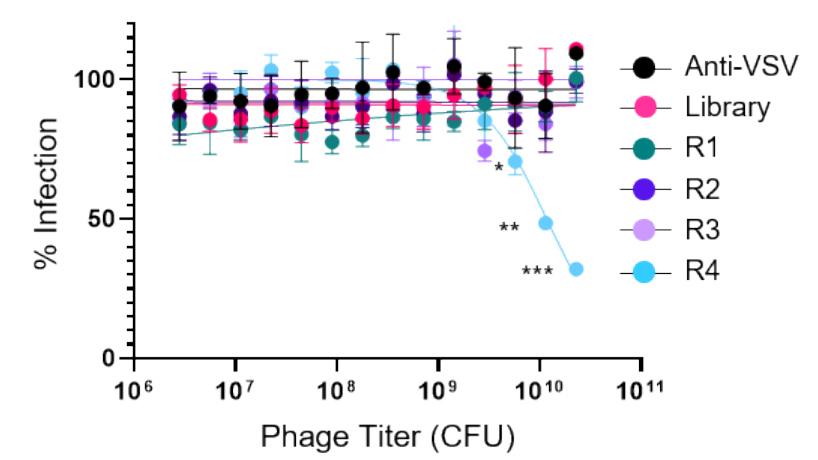

Fig. 1: Development of high-diversity $\mathrm{V}_{\mathrm{H}} \mathrm{H}$ library and screening campaign for SARS-2 neutralizing $\mathbf{V}_{\mathrm{H}} \mathrm{H}$ 's. A) Library design using deposited sequences of functional $\mathrm{V}_{\mathrm{H}} \mathrm{H}$ 's from various sources. Data was mined to determine optimal CDR length and amino acid prevalence at each amino acid position within each respective CDR. B) Schematic for the biopanning approach used to identify neutralizing $V_{H} H$ 's directed to the SARS-2 RBD. C) Polyclonal ELISA against multiple antigens show enrichment of a positive SARS2 binding population of displayed $\mathrm{V}_{\mathrm{H}} \mathrm{H}$ with each sequential round of panning. Data is from experimental conditions performed in triplicate; the error is the standard deviation from the mean. D) Neutralization of VSV-SARS-2 GFP viral infection with polyclonal $V_{H} H$ displaying phage from each round of panning. Data is from experimental conditions performed in triplicate; the error is the standard deviation from the mean ${ }^{* * *}, \mathrm{P}<0.001$; $\left.{ }^{* *}, \mathrm{P}<0.01 ;{ }^{*}, \mathrm{P}<0.05\right)$. The data represent one of 3 experiments with similar results. 
A. 384 colonies selected for clonal phage

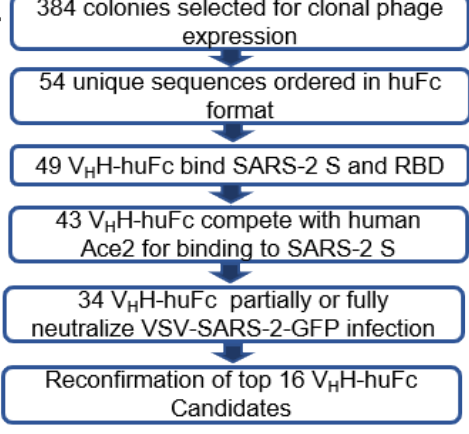

D. Competition of ACE2 Binding to

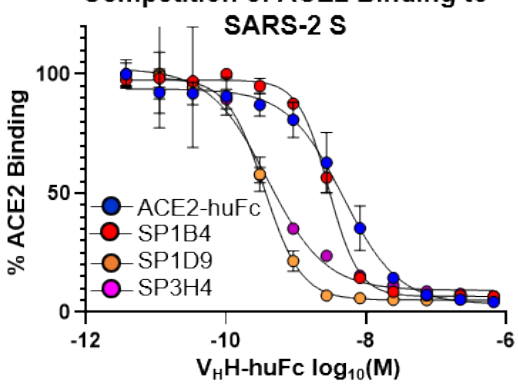

G.

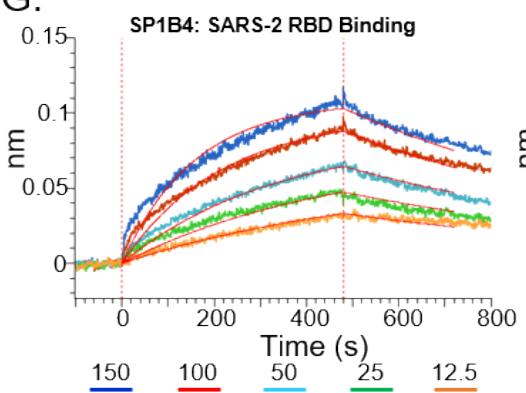

B. Binding to SARS-2 S

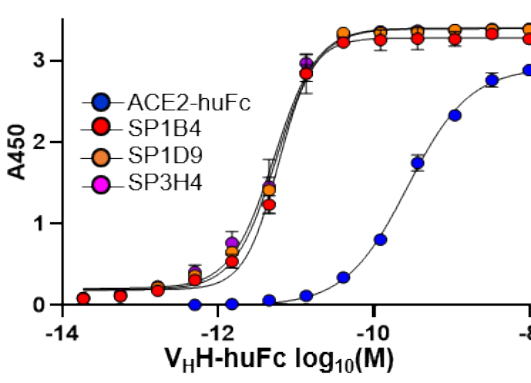

E. Neutralization of VSV-SARS-2-GFP $F$

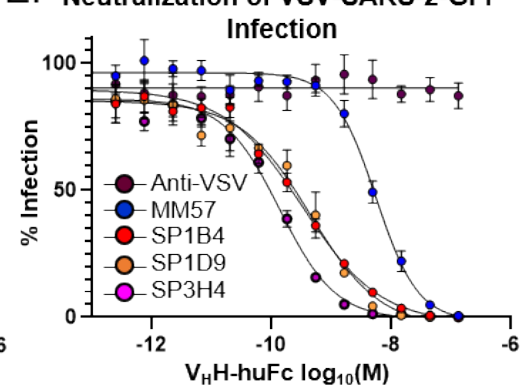

H.

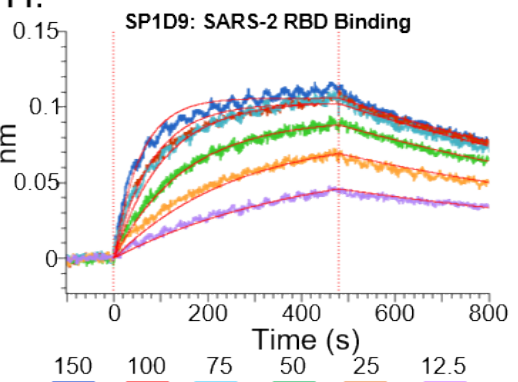

C. Binding to SARS-2 RBD

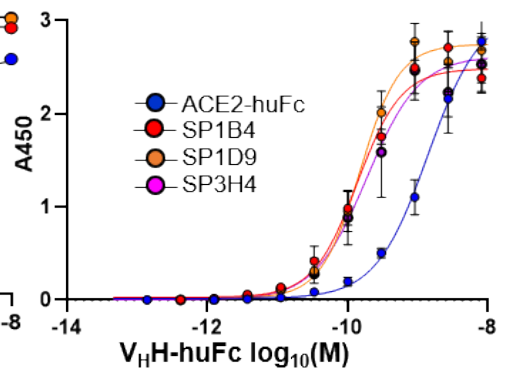

F. Neutralization of WT SARS-2
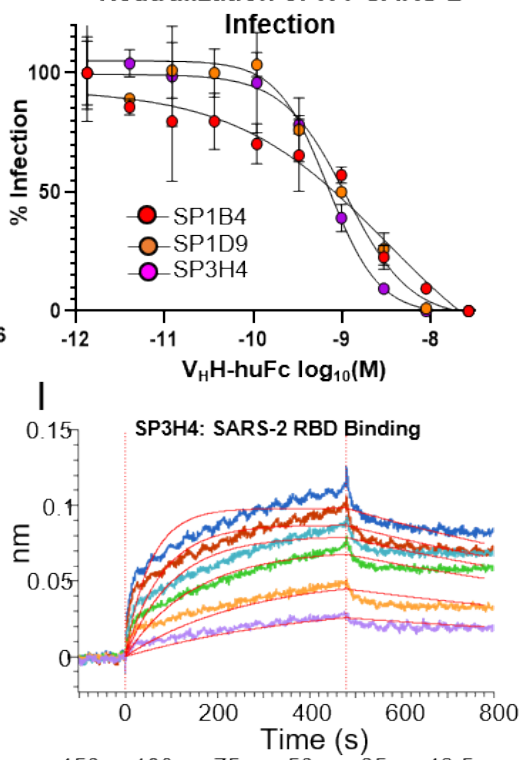

$\underline{150} \quad \underline{100} \quad \underline{75} \quad \underline{50} \quad \underline{25} \quad \underline{12.5}$
860 J.

\begin{tabular}{ccc}
$\mathbf{V}_{\mathrm{H}} \mathrm{H}$-huFc & $\mathrm{K}_{\mathrm{D}}(\mathrm{nM})$ & $\mathrm{K}_{\mathrm{a}}($ \\
\hline \hline SP1B4 & 39.5 & 3.35 \\
\hline SP1D9 & 8.9 & 1.12 \\
\hline SP3H4 & Biphasic & Bip
\end{tabular}

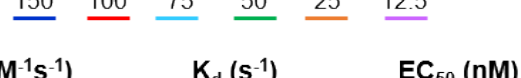

861

862

863

864

865

Fig. 2: Evaluation of $\mathrm{V}_{\mathrm{H}} \mathrm{H}-\mathrm{huFc}$ candidates. A) Triage flowchart for selection of top candidates, from clonal phage ELISA to selection of 16 candidates for reconfirmation. B) Reconfirmation ELISA of top three candidates binding to SARS-2 S and C) SARS-2 RBD. D) Top candidate $V_{H} H$-huFc's compete with ACE2-huFc for binding to SARS-2 $S$ by competition ELISA and E) neutralize VSV-SARS-2 GFP infection of Vero cells. The data for a-e are from experimental conditions performed in triplicate, the error is the standard deviation from the mean. F) All three $\mathrm{V}_{\mathrm{H}} \mathrm{H}$-huFc's also neutralize WT SARS-2 in a plaque reduction neutralization assay. The data from this is the mean of the plaque assay performed in duplicate, the error is the standard deviation from the mean. BLI sensograms show binding to SARS-2 RBD by SP1B4 (G), SP1D9 (H), and SP3H4 (I). At least 5 concentrations were used for global fit analysis. J) Table summarizing kinetic properties, neutralizing efficacy, and thermal stability properties for SP1B4, SP1D9, and SP3H4. Melting temperatures from DSF were determined from two independent experiments each performed in triplicate. 
A.

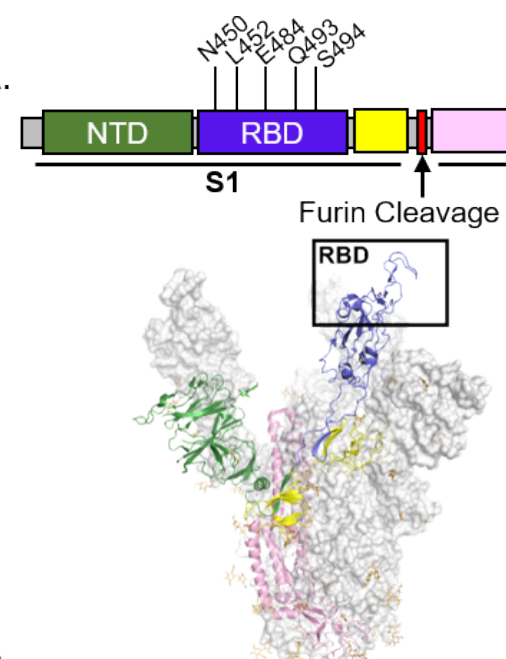

C.

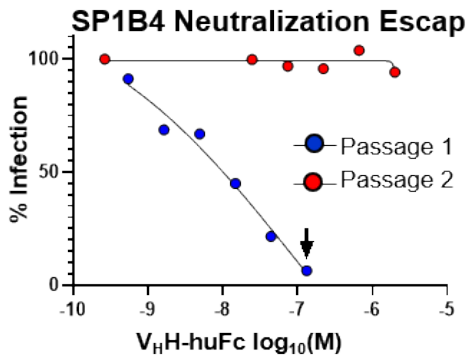

D

B.
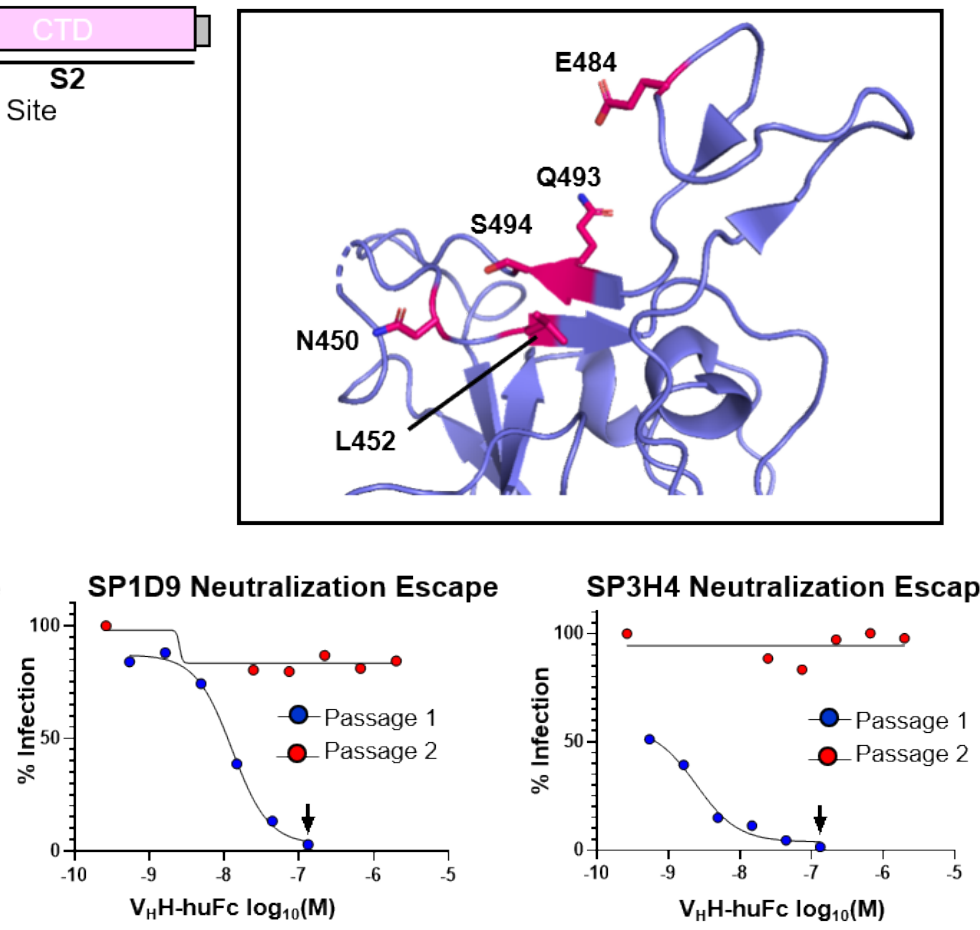

875

876

877

878

879

880

881

882

883

884

885

886

887

888

889

890

\begin{tabular}{|c|c|c|c|c|c|c|c|c|c|c|}
\hline & & WT & $\mathrm{N} 450 \mathrm{~K}$ & L452R & E484K & E484A & Q493R & S494P & B.1.1.7 & B.1.351 \\
\hline $\begin{array}{l}\text { ACE2- } \\
\text { huFc }\end{array}$ & $\mathrm{K}_{\mathrm{D}}(\mathrm{nM})$ & 13.3 & 19.8 & 16.3 & 25.6 & 13.5 & 17.4 & 16.9 & 2.5 & 10.1 \\
\hline \multirow{3}{*}{ SP1B4 } & Passage 1 & $\therefore$ & $30 \%$ & $0 \%$ & $30 \%$ & $3 \%$ & $14 \%$ & $10 \%$ & $\therefore$ & - \\
\hline & Passage 2 & $\because$ & $10 \%$ & $0 \%$ & $17 \%$ & $19 \%$ & $46 \%$ & $43 \%$ & $\because$ & $\because$ \\
\hline & $\mathrm{K}_{\mathrm{D}}(\mathrm{nM})$ & 16 & N.B & N.B. & N.B. & N.B. & N.B. & N.B. & 97.7 & N.B. \\
\hline \multirow{3}{*}{ SP1D9 } & Passage 1 & $\therefore$ & $0 \%$ & $0 \%$ & $44 \%$ & $0 \%$ & $6 \%$ & $26 \%$ & $\therefore$ & $\therefore$ \\
\hline & Passage 2 & $\because$ & $0 \%$ & $0 \%$ & $10 \%$ & $0 \%$ & $23 \%$ & $63 \%$ & $\cdots$ & $\because$ \\
\hline & $\mathrm{K}_{\mathrm{D}}(\mathrm{nM})$ & 8.9 & 10.7 & 51.8 & N.B. & 32.8 & N.B. & N.B. & 49.7 & N.B. \\
\hline \multirow{3}{*}{ SP3H4 } & Passage 1 & - & $24 \%$ & $23 \%$ & $12 \%$ & $21 \%$ & $0 \%$ & $0 \%$ & - & - \\
\hline & Passage 2 & $\because$ & $10 \%$ & $59 \%$ & $4 \%$ & $19 \%$ & $0 \%$ & $0 \%$ & & \\
\hline & $\mathrm{K}_{\mathrm{D}}(\mathrm{nM})$ & Biphasic & N.B. & 64.7 & N.B. & N.B. & N.B. & N.B. & Biphasic & N.B. \\
\hline
\end{tabular}

Fig. 3: Genereation and Characterization of VHH Neutralization Escape Mutants. A) Subdomains of the SARS-2 S gene are color coded with correspoding structural context (PDB: 7CAK). Loci of mutations on $\mathrm{S}$ gene from NGS evaluation of virus supernatant from virus infected cells passaged in the presence of $\mathrm{V}_{\mathrm{H}} \mathrm{H}$ - antibodies. In this structure the RBD is in the "up" position. B) The RBD is designated with the dominant mutations characterized in this study (magenta). C) VSV-SARS-2-GFP neutralization escape occurs in a single passage. VSV-SARS-2-GFP neutralization is recorded $12 \mathrm{hpi}$. The black arrow designated the well from which the virus-containing supernatant was taken and diluted for the second passage. Data for this is from a single replicate. D) NGS and kinetic summary of each of the neutralization escape mutant profiles for SP1B4, SP1D9, and $\mathrm{SP} 3 \mathrm{H} 4$. Dissociation constants for each individual RBD mutation with ACE2-huFc and $\mathrm{V}_{\mathrm{H}} \mathrm{H}$-huFc antibodies. N.B. = no binding observed at $150 \mathrm{nM}$ SARS-2 RBD by BLI (S7-9 Fig.). Sensograms were designated biphasic if they did not agree with a global 1:1 fit analysis. The prevalence of each escape mutation is presented as a percentage at that amino acid postion and is conditionally colored with increasing intesity of red. 


\section{A. Prophylactic Treatment}

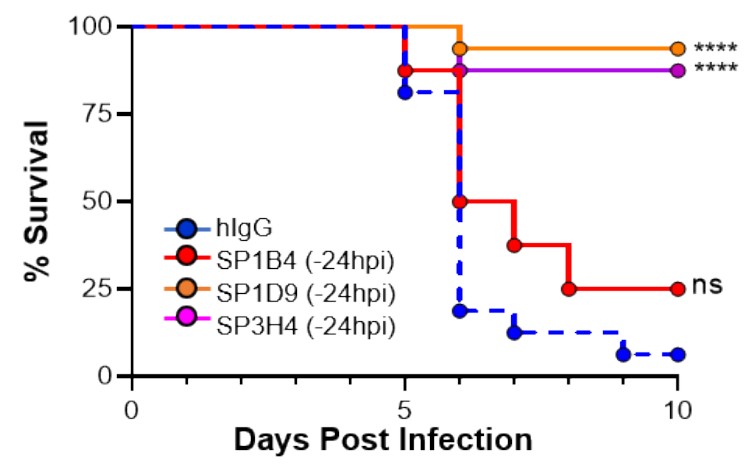

C.

\section{Therapeutic Treatment}

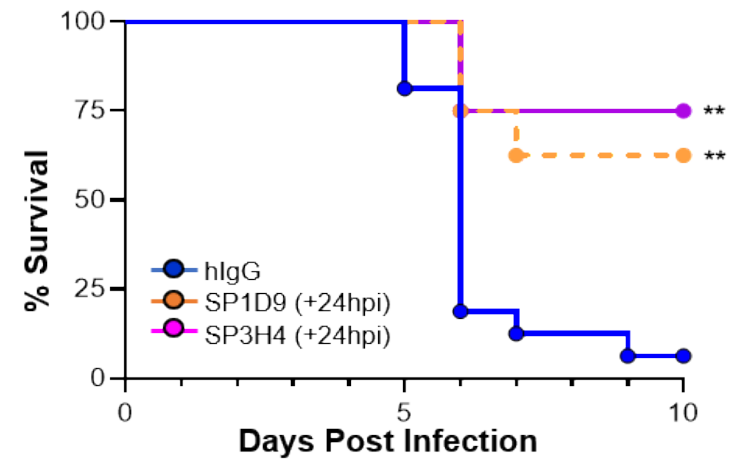

B. Prophylactic Group Weight to Day 6

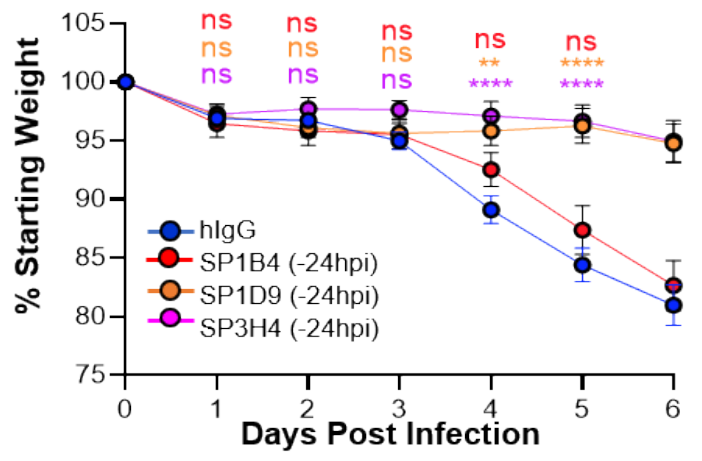

D.

Therapeutic Group Weight to Day 6

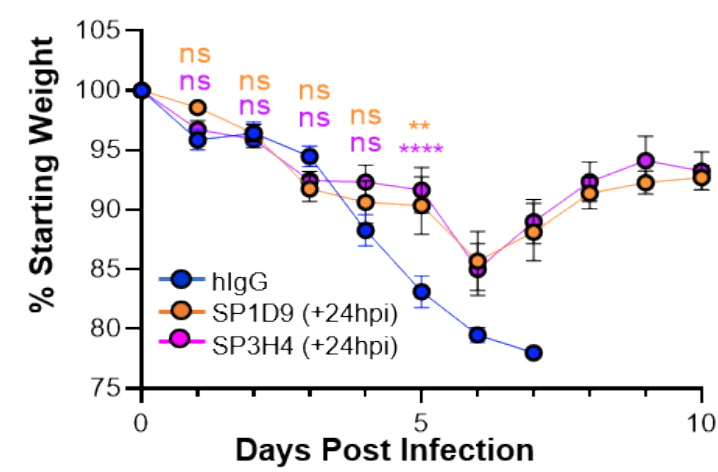

Fig. 4: Top $\mathrm{V}_{\mathrm{H}} \mathrm{H}$ candidates provide protection from lethal SARS-2 infection in vivo. Kaplan-Meier curve illustrating percentage survival of K18-hACE2 mice infected intranasally with $2.5 \times 10^{4} \mathrm{PFU}$ SARS-2 and dosed with $10 \mathrm{mg} / \mathrm{kg} \mathrm{V}_{\mathrm{H}} \mathrm{H}$-huFc via intraperitoneal injection prophylactically (A) at 24 hours prior to infection or therapeutically (C) at $24 \mathrm{hpi}$. A log rank test was performed with Bonferroni multiple comparison correction applied. B) Percentage weight loss for mice in (A). D) Percentage weight loss for mice in (C). For (B) and (D), statistical analyses were performed at time points when all mice were alive to avoid survivor bias. Data displayed are the mean $+/$ - standard error of the mean. A \& B) Isotype control $n=16$, SP1B4 (-24 hpi) $n=8$, SP1D9 (-24 hpi) $n=16$, SP3H4 (-24 hpi) n=16. C \& D) Isotype control n=8, SP1D9 (+24 hpi) n=8, SP3H4 (+24 hpi) $n=8$. Data represent two experiments $\left({ }^{* * *} p<0.0001 ;{ }^{* *} p<0.01\right.$; ns=not significant).

\section{Supporting Information Captions}

S1 Fig. Distribution of the lengths of CDR loops 1-3 of $670 \mathrm{VHH}$ sequences deposited in the Single Domain Antibody Database (sdAB-DB).

S2 Fig. Monoclonal Phage-VHH screening for SARS-2 S and RBD specific binding clones: ELISA with 384 clonal VHH-displaying phage preparations with SARS-2 S (left), SARS-2 RBD (center), and BSA (right). 
S3 Fig. Triage of VHH-huFc candidates: A) ELISA with $54 \mathrm{VHH}$-huFc with SARS-2 S (left), SARS-2 RBD (center), and BSA (right). The data are from experimental conditions performed in triplicate, the error is the standard deviation from the mean.

S4 Fig. Reconfirmation of Purified VHH-huFc candidates: A) ELISA with $16 \mathrm{VHH}$-huFc antibodies with SARS-2 S. B) Binding of $16 \mathrm{VHH}$-huFc candidates to SARS-2 RBD. C) Competition ELISA with the VHH-huFc antibodies. D) Neutralization of VSV-SARS-2GFP infection of Vero cells. MM57 is a control anti-SARS-2 neutralizing monoclonal antibody from Sino Biological. The anti-VSV monoclonal antibody was produced from hybridoma line CRL-2700 (ATCC). E) VHH-huFc antibodies do not neutralize SARS-1 pseudotyped VSV demonstrating specificity for SARS-2 S. M396 is an anti-SARS-1 antibody produced by GenScript. The data for a-e are from experimental conditions performed in triplicate, the error is the standard deviation from the mean.

S5 Fig. Differential scanning fluorimetry to determine $\mathrm{VHH}$-huFc melting temperatures.

S6 Fig. BLI Sensograms for ACE2-huFc binding to SARS-2 RBD variants and escape mutants.

S7 Fig. BLI Sensograms SP1B4 binding to SARS-2 RBD variants and escape mutants.

S8 Fig. BLI Sensograms SP1D9 binding to SARS-2 RBD variants and escape mutants.

S9 Fig. BLI Sensograms SP3H4 binding to SARS-2 RBD variants and escape mutants.

S10 Fig. Weight change for individual mice from preclinical evaluation of $\mathrm{VHH}-\mathrm{huFc}$ antibodies.

S1 Table: Next-Generation Sequencing Results for VHH Library Diversity

S2 Table: Next-Generation Sequencing Results for VHH Library CDR3 Length Distribution

S3 Table: Quantification of Phage from Biopanning Campaign against SARS-2 S and RBD

S4 Table: Summary of ELISA, Competition ELISA and neutralization of VSV-SARS-2GFP infection of Vero cells for VHH-huFc's ( $\mathrm{Y}=\mathrm{Yes}, \mathrm{N}=\mathrm{No}, \mathrm{NT}=$ not tested

S5 Table: Summary of Neutralization of VSV-SARS-2-GFP, SARS-2-NG, and SARS-2 infection of Vero cells for reconfirmation VHH-huFc antibodies.

S6 Table: Summary of BLI data for escape mutant and SARS-2 variant's 
A. 384 colonies selected for clonal phage expression

54 unique sequences ordered in huFc
format

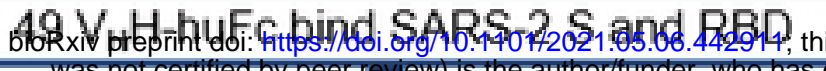

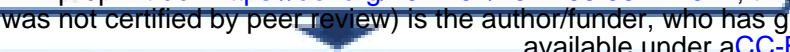

$43 \mathrm{~V}_{\mathrm{H}} \mathrm{H}$-huFc compete with human

Ace2 for binding to SARS-2 S

$34 \mathrm{~V}_{\mathrm{H}} \mathrm{H}$-huFc partially or fully neutralize VSV-SARS-2-GFP infection $\checkmark$

Reconfirmation of top $16 \mathrm{~V}_{\mathrm{H}} \mathrm{H}$-huFc Candidates

D. Competition of ACE2 Binding to

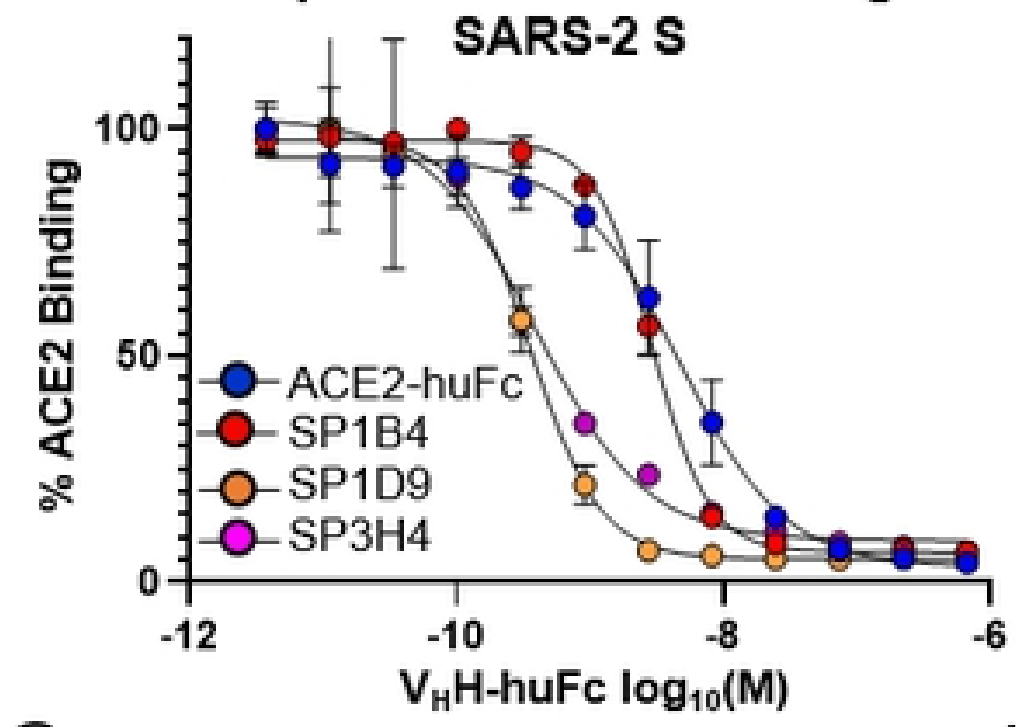

G.

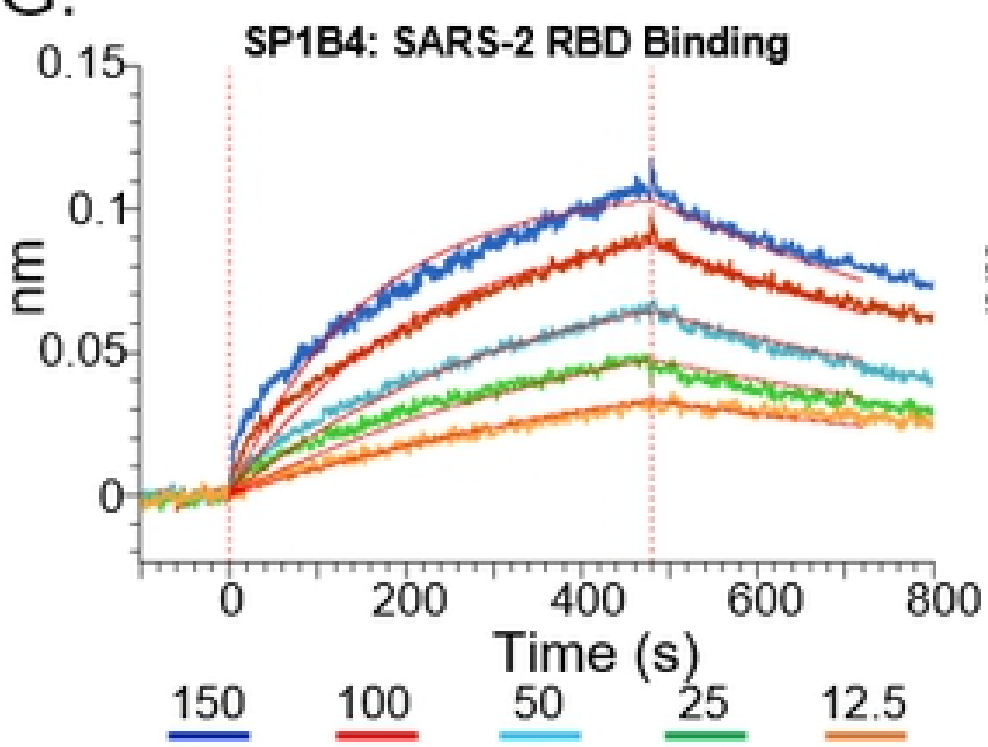

B.

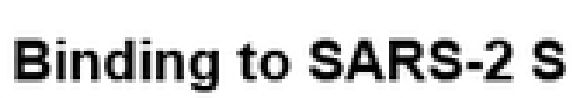

C.
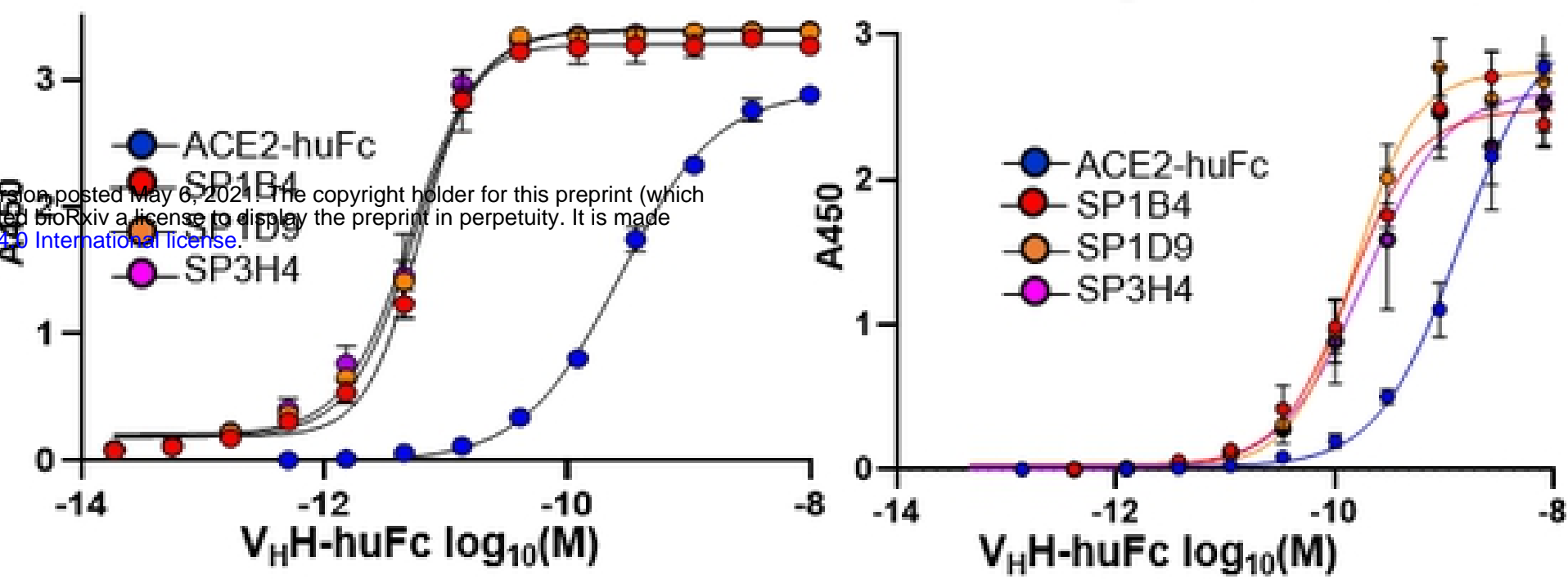

E. Neutralization of VSV-SARS-2-GFP F.

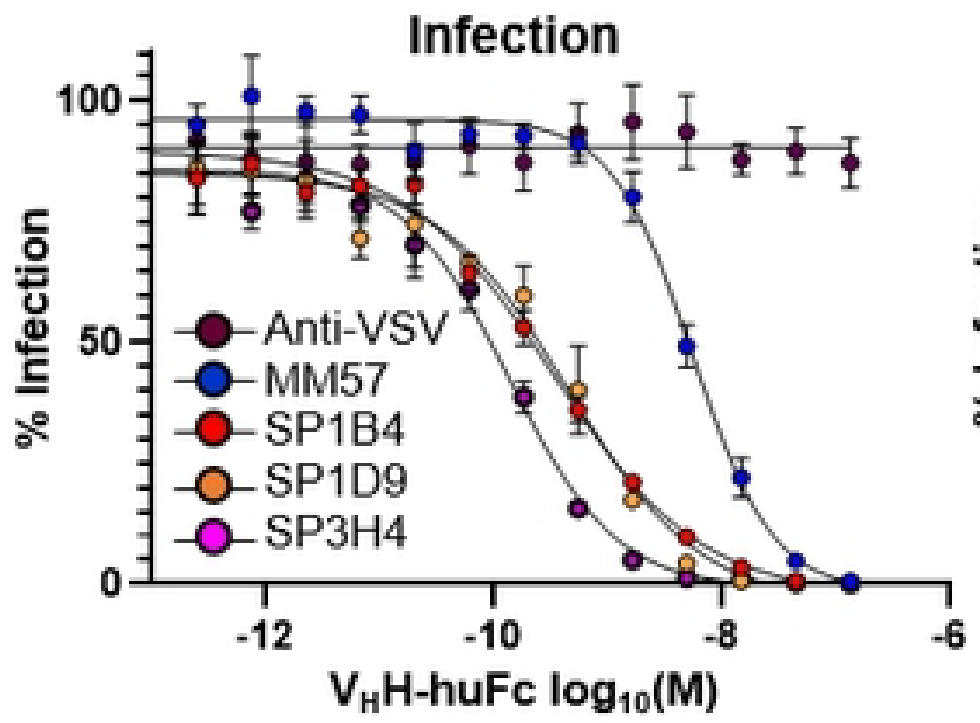

$\mathrm{H}$.

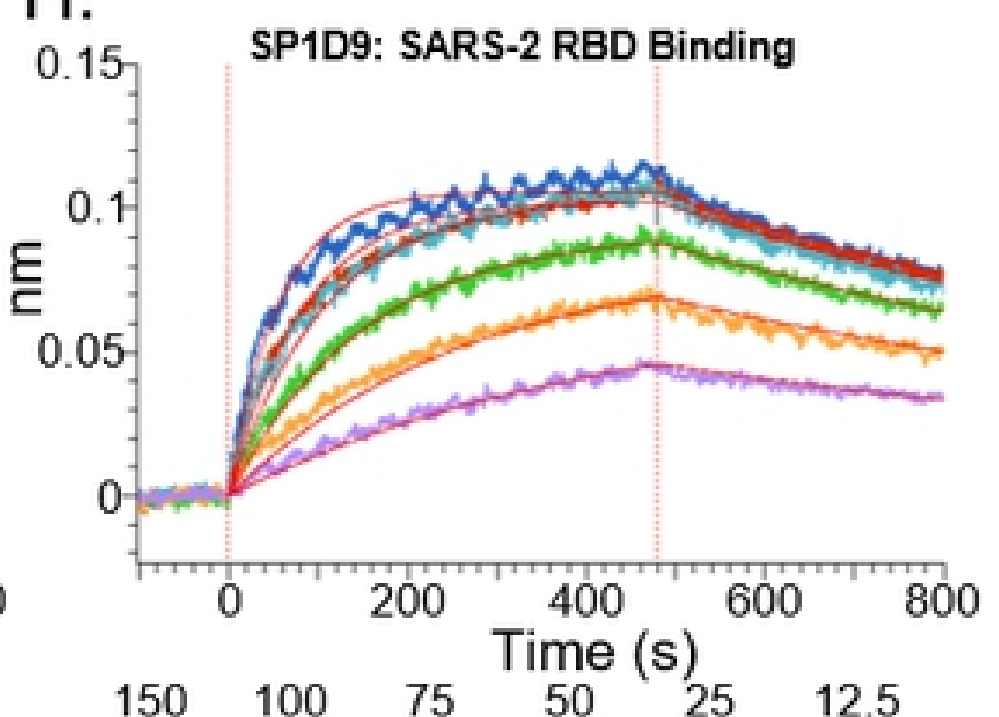

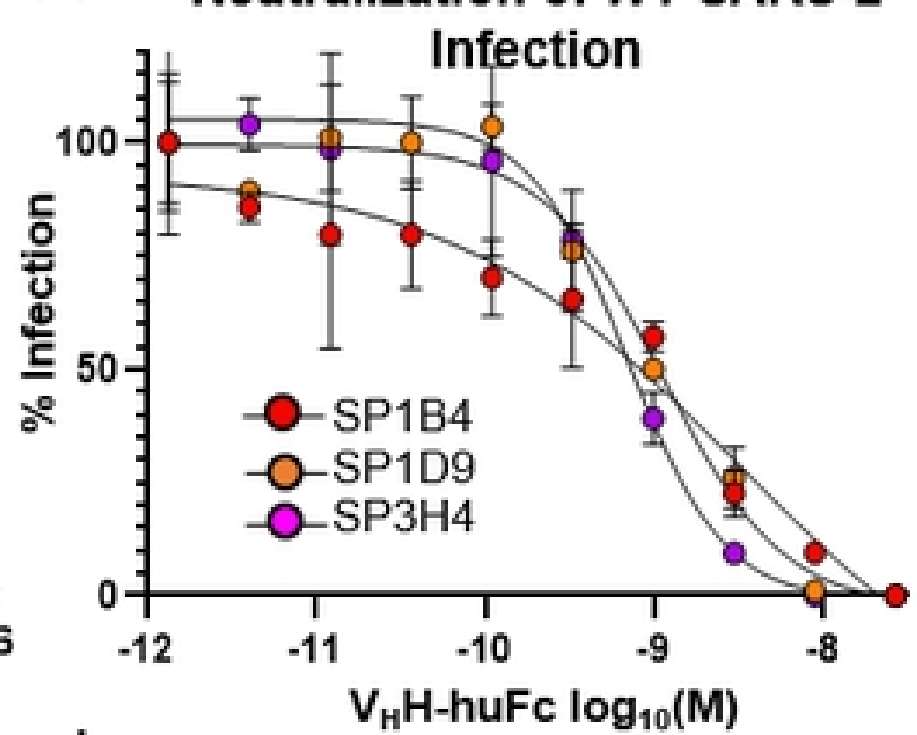

I

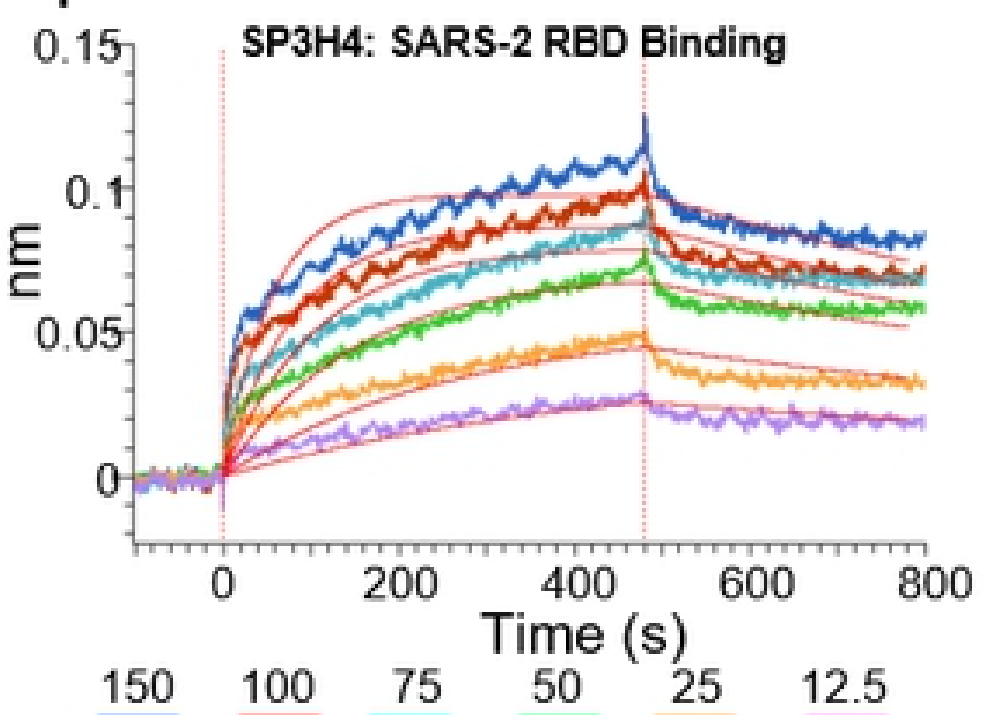

J.

\begin{tabular}{ccccccc}
$\mathbf{V}_{\mathrm{H}} \mathrm{H}-\mathrm{huFc}$ & $\mathrm{K}_{\mathrm{D}}(\mathrm{nM})$ & $\mathrm{K}_{\mathrm{a}}\left(\mathbf{M}^{-1} \mathbf{s}^{-1}\right)$ & $\mathbf{K}_{\mathrm{d}}\left(\mathbf{s}^{-1}\right)$ & $\mathbf{E C}_{50}(\mathrm{nM})$ & PRNT $_{50}(\mathrm{nM})$ & $\mathbf{T}_{\mathrm{m}}\left({ }^{\circ} \mathbf{C}\right)$ \\
\hline \hline SP1B4 & 39.5 & $3.35 \times 10^{4}$ & $1.32 \times 10^{-3}$ & 0.33 & 3.14 & 60.4 \\
\hline SP1D9 & 8.9 & $1.12 \times 10^{5}$ & $9.99 \times 10^{-4}$ & 0.45 & 1.12 & 64.1 \\
\hline SP3H4 & Biphasic & Biphasic & Biphasic & 0.14 & 0.70 & 61.0 \\
\hline
\end{tabular}

Figure 2 
bioRxiv preprint doi: https://doi.org/10.1101/2021.05.06.442911; this version posted May 6, 2021. The copyright holder for this preprint (which

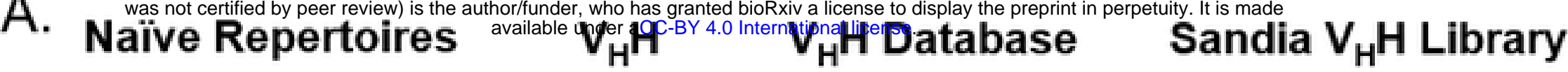

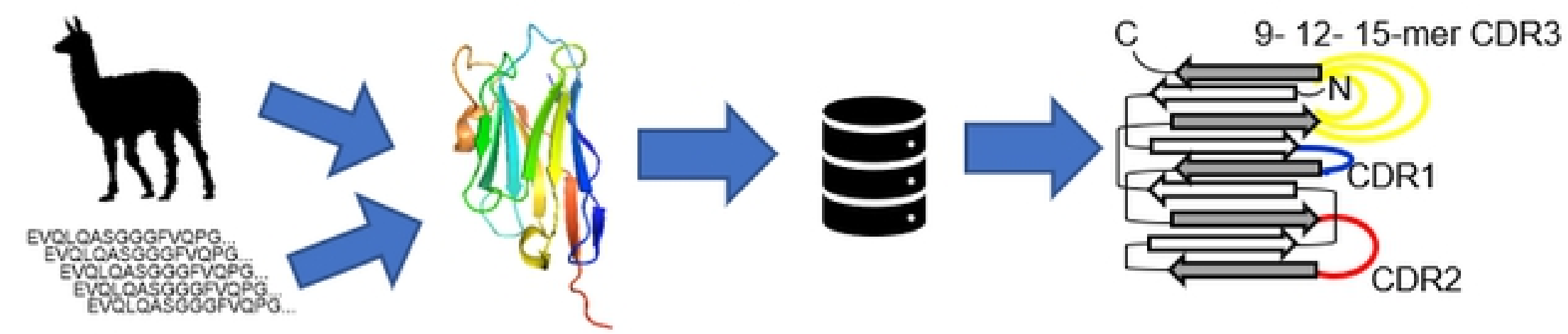

Synthetic Sources

B.

Full SARS-CoV-2 S SARS-CoV-2 RBD

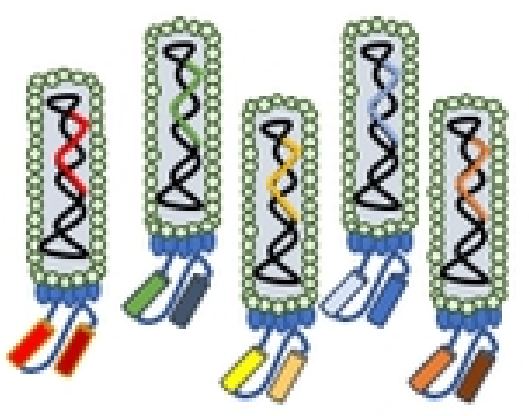

High-Diversity $\mathrm{V}_{\mathrm{H}} \mathrm{H}$

Library $3.2 \times 10^{10}$

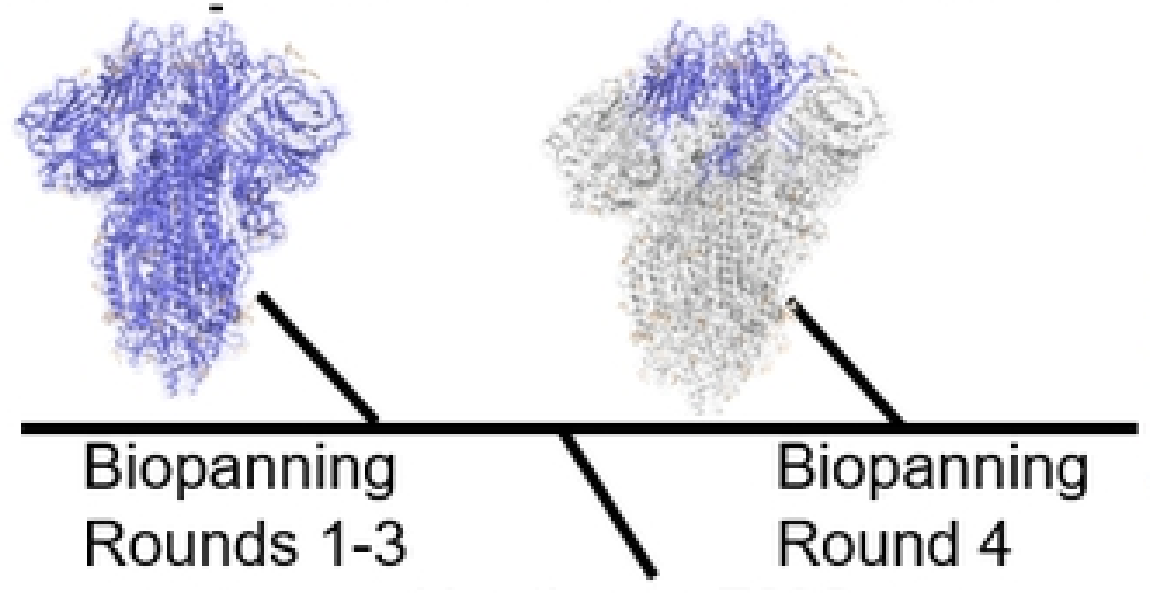

Heating to $70^{\circ} \mathrm{C}$ 15 minutes

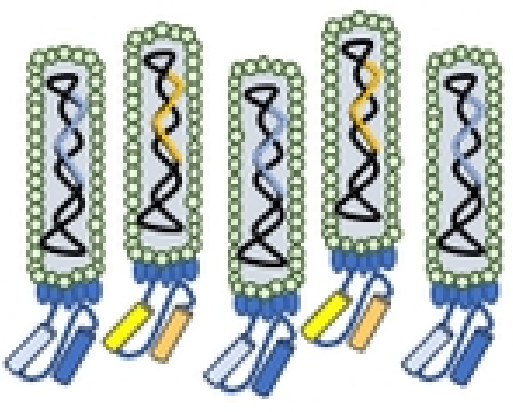

54 Unique RBD

Targeted Clones
C. Enrichment of SARS-2 Binding Phage

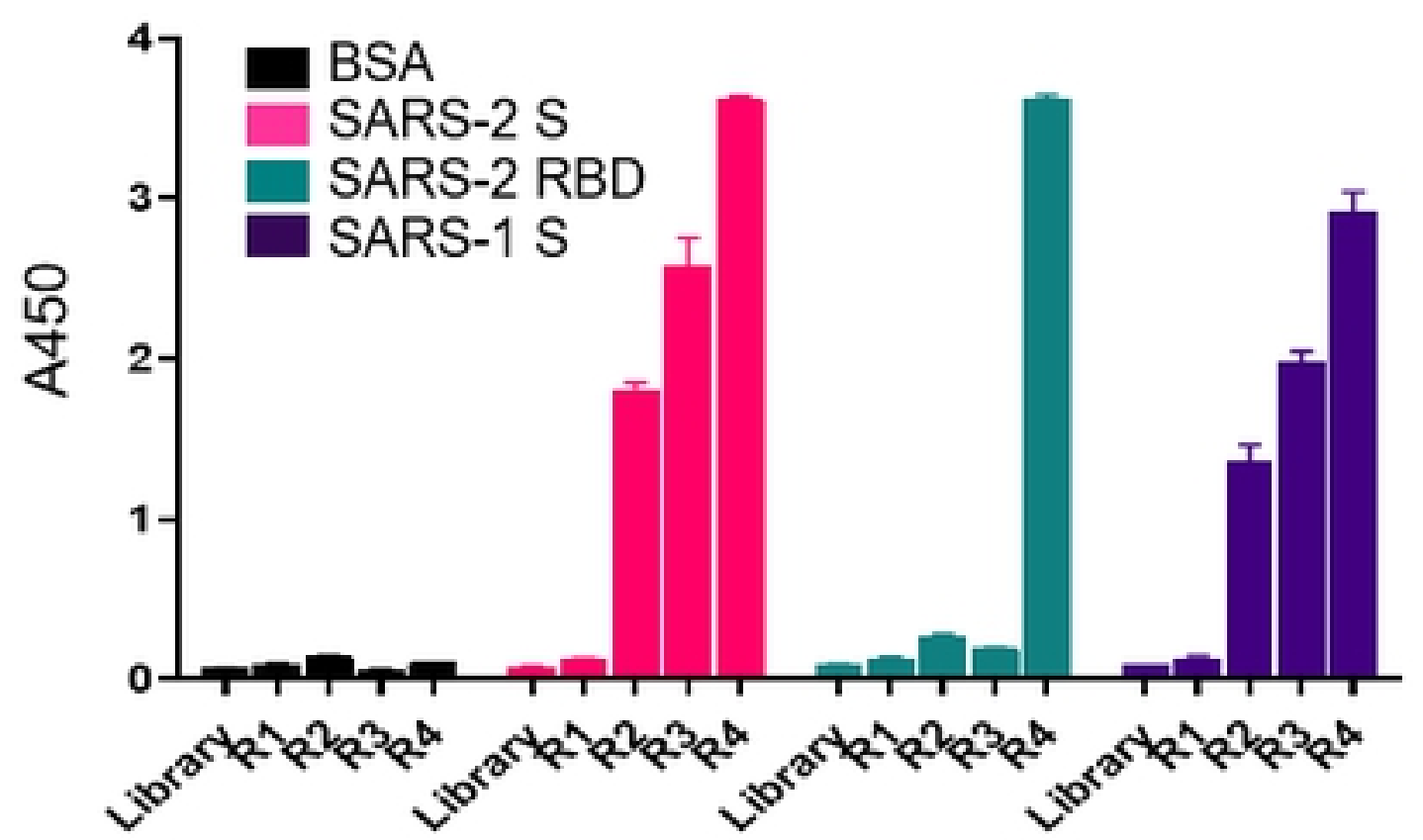

D. Enriched Phage Neutralization of VSV-SARS-2-GFP

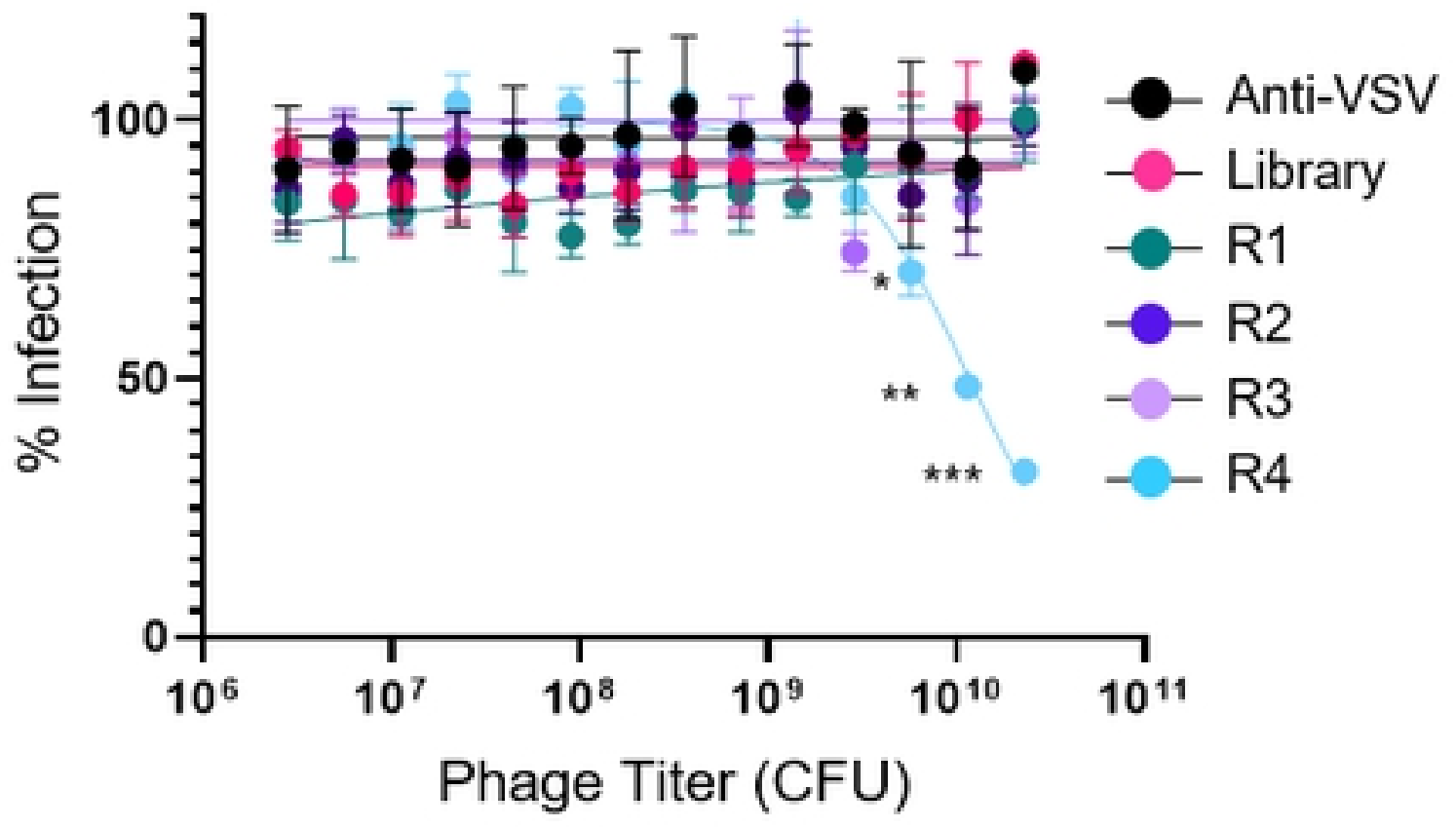

Figure 1 
A.

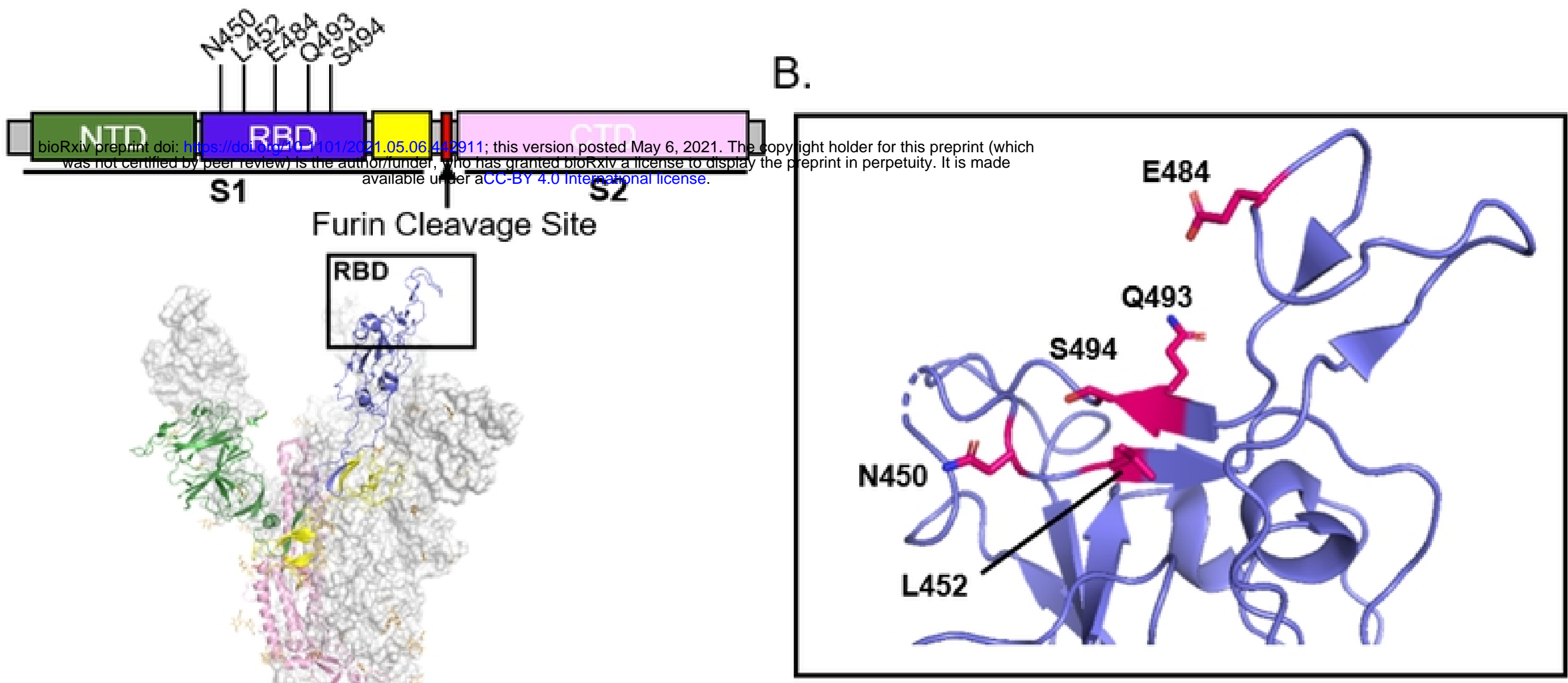

C.
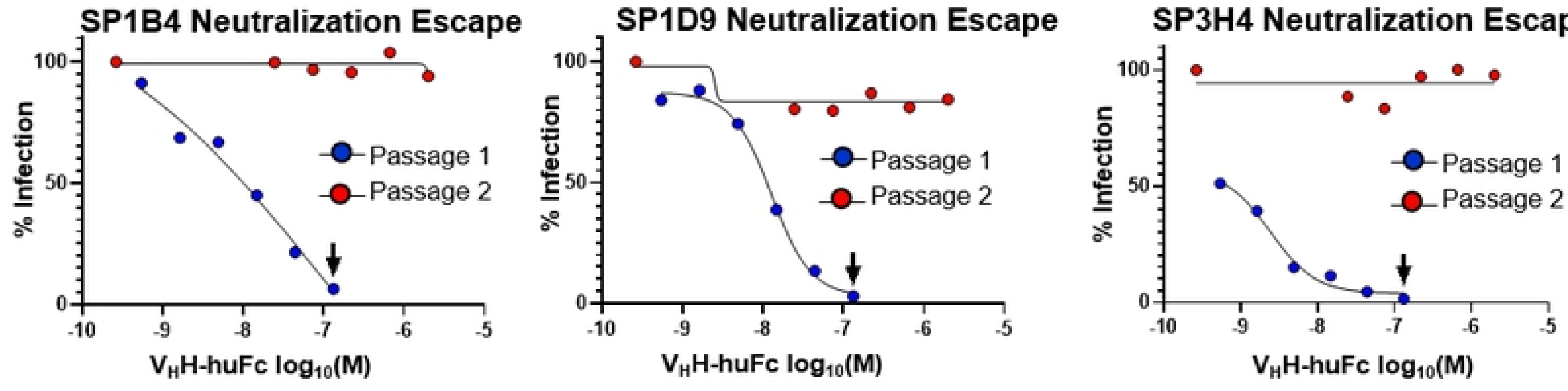

\begin{tabular}{|c|c|c|c|c|c|c|c|c|c|c|}
\hline & & WT & N450K & L452R & E484K & E484A & Q493R & S494P & B.1.1.7 & B.1.351 \\
\hline $\begin{array}{l}\text { ACE2- } \\
\text { huFc }\end{array}$ & $\mathrm{K}_{\mathrm{D}}(\mathrm{nM})$ & 13.3 & 19.8 & 16.3 & 25.6 & 13.5 & 17.4 & 16.9 & 2.5 & 10.1 \\
\hline \multirow{3}{*}{ SP1B4 } & Passage 1 & $\therefore$ & $30 \%$ & $0 \%$ & $30 \%$ & $3 \%$ & $14 \%$ & $10 \%$ & -8 & - \\
\hline & Passage 2 & $\because$ & $10 \%$ & $0 \%$ & $17 \%$ & $19 \%$ & $46 \%$ & $43 \%$ & - & - \\
\hline & $\mathrm{K}_{\mathrm{D}}(\mathrm{nM})$ & 16 & N.B & N.B. & N.B. & N.B. & N.B. & N.B. & 97.7 & N.B. \\
\hline \multirow{3}{*}{ SP1D9 } & Passage 1 & $\therefore$ & $0 \%$ & $0 \%$ & $44 \%$ & $0 \%$ & $6 \%$ & $26 \%$ & - & - \\
\hline & Passage 2 & $\because$ & $0 \%$ & $0 \%$ & $10 \%$ & $0 \ddot{0} \%$ & $23 \%$ & $63 \%$ & $\because$ & $\because$ \\
\hline & $\mathrm{K}_{\mathrm{D}}(\mathrm{nM})$ & 8.9 & 10.7 & 51.8 & N.B. & 32.8 & N.B. & N.B. & 49.7 & N.B. \\
\hline \multirow{3}{*}{ SP3H4 } & Passage 1 & $\therefore$ & $24 \%$ & $23 \%$ & $.12 \%$ & $21 \%$ & $.0 \%$ & $0 \%$ & $\therefore$ & $\therefore$ \\
\hline & Passage 2 & $\because$ & $10 \%$ & $59 \%$ & $4 \%$ & $19 \%$ & $0 \%$ & $0 \%$ & & \\
\hline & $\mathrm{K}_{\mathrm{D}}(\mathrm{nM})$ & Biphasic & N.B. & 64.7 & N.B. & N.B. & N.B. & N.B. & Biphasic & N.B. \\
\hline
\end{tabular}

Figure 3 
A. Prophylactic Treatment

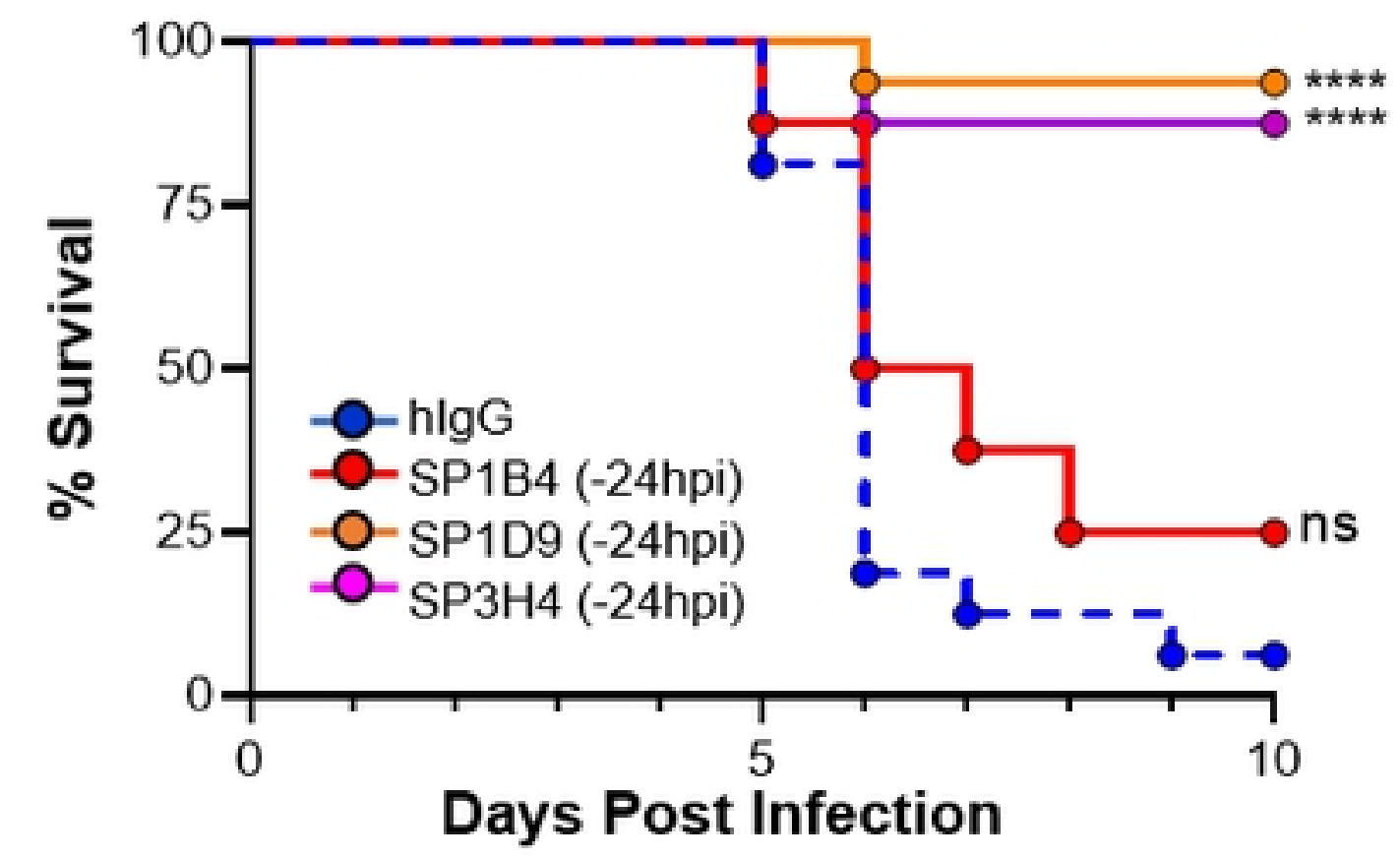

C.

\section{Therapeutic Treatment}

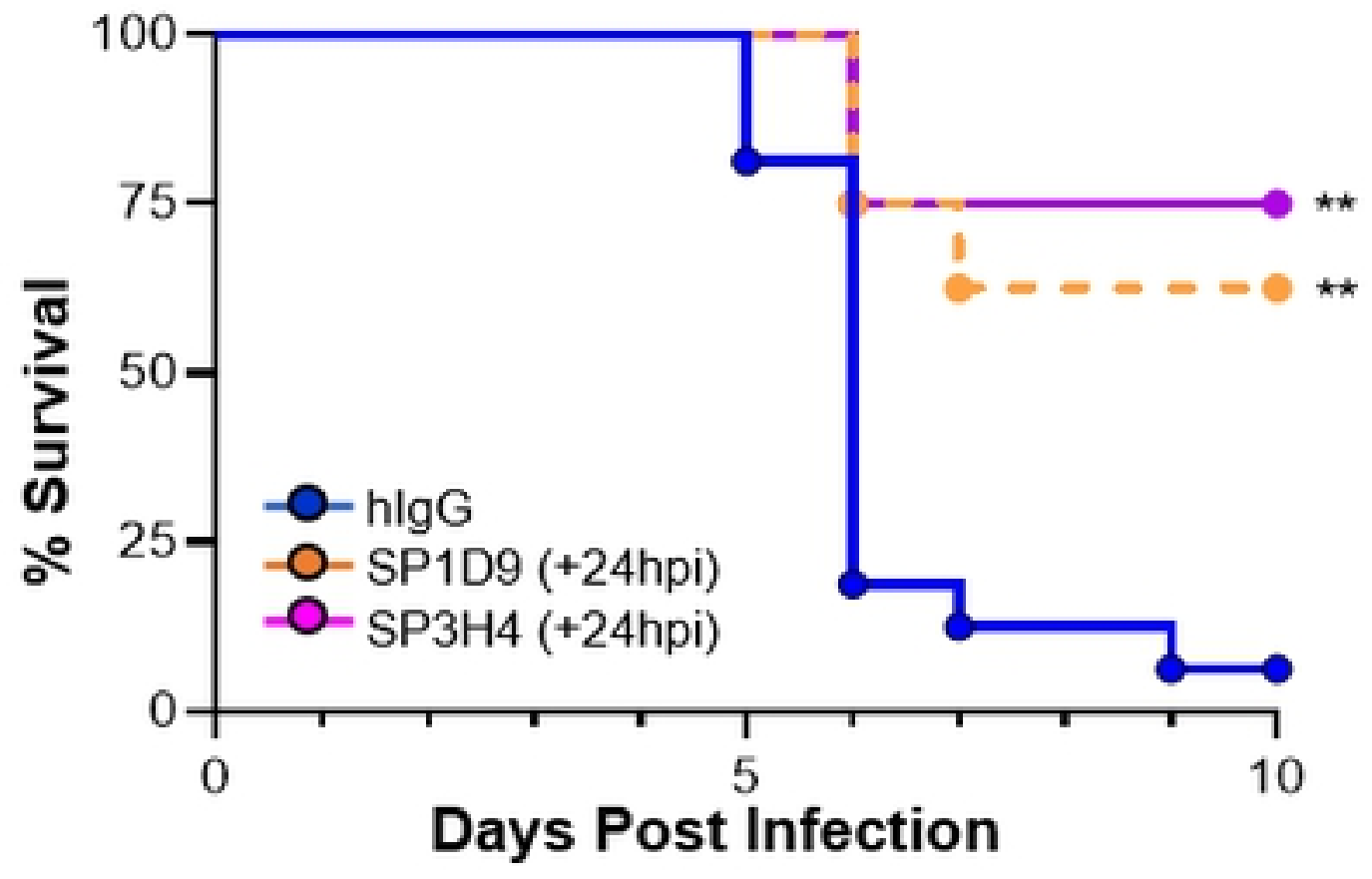

B. Prophylactic Group Weight to Day 6

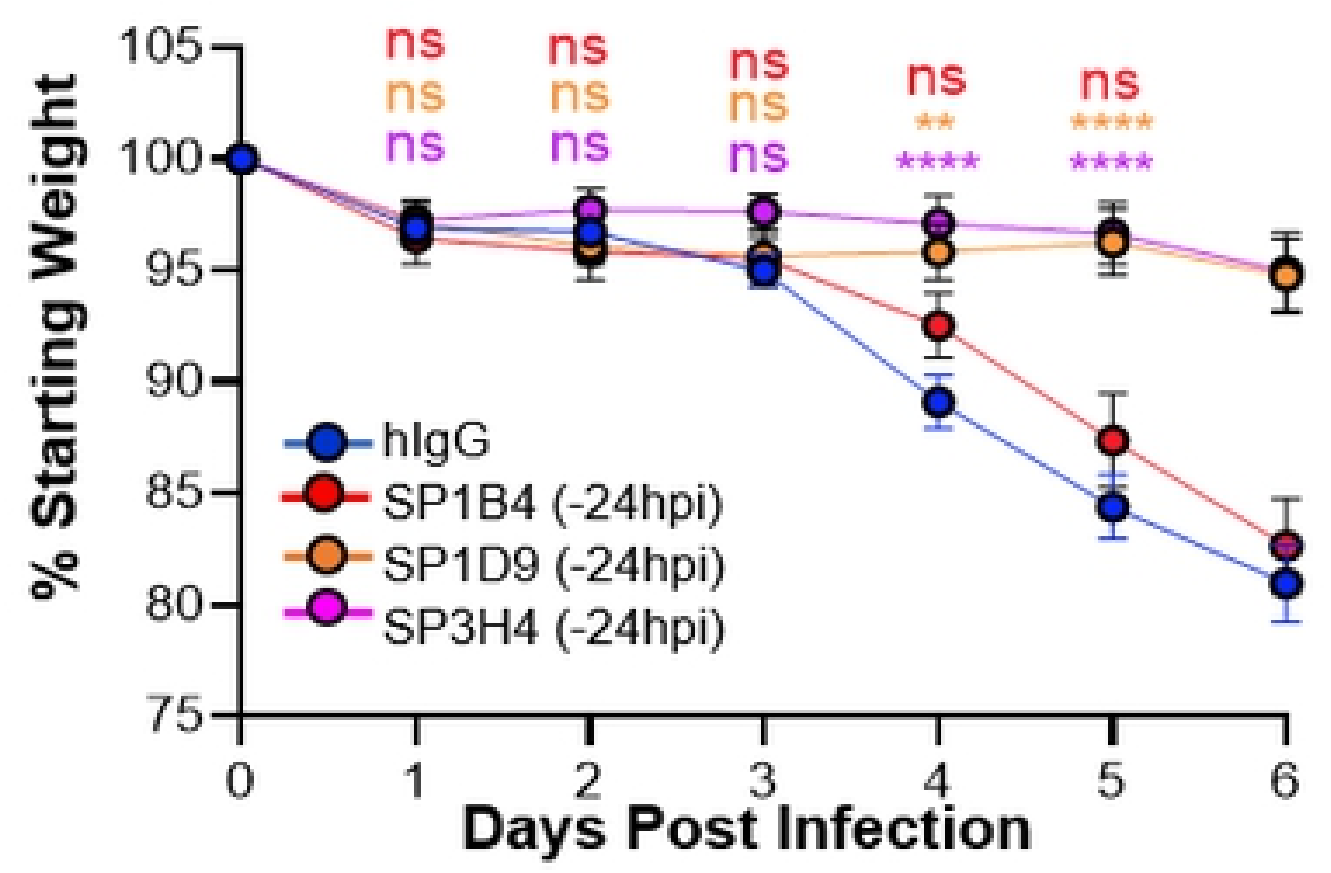

D.

\section{Therapeutic Group Weight to Day 6}

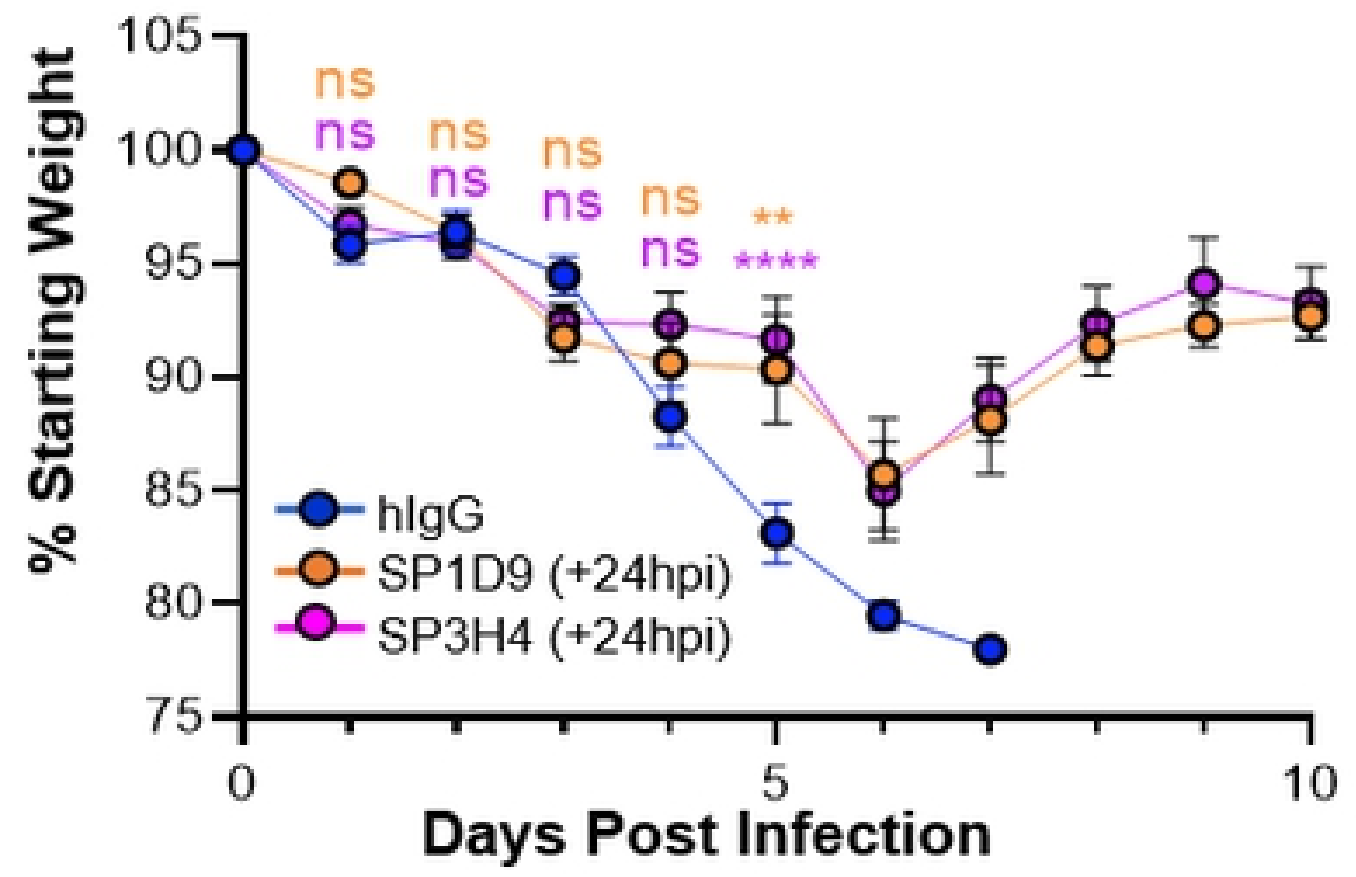

Figure 4 